\title{
Reyes, edades y épocas del Perú prehispánico
}

\author{
JUAN J. R. VILLARÍAS ROBLES \\ Instituto de la Lengua Española. CSIC. Madrid
}

\section{RESUMEN}

La historia del Perú prehispánico se encuentra en un estado de incertidumbre desde que la antropología cognitiva (en la década de 1940), y después la estructuralista (en los años sesenta y setenta), pusieran en entredicho el valor documental de la clase de fuentes aceptadas hasta entonces para reconstruir esa historia. Estas fuentes son textos escritos después del comienzo de la conquista española del territorio, en el siglo xvI. En la década de 1940, su contenido comenzó a ser visto y analizado como mitológico y no como histórico. Pero este revolucionario planteamiento no ha sido aceptado por muchos especialistas, que siguen asumiendo que esos textos pueden ser tratados como fuentes históricas en el sentido más convencional de la expresión. El autor entiende que la clave para superar este desencuentro reside en los conceptos nativos de historia, tiempo y espacio y propone una vía de solución al problema tras examinar críticamente las principales aportaciones de unos y otros investigadores. En el fondo se trata de articular adecuadamente estructura e historia en la comprensión de una tradición cultural muy diferente a la nuestra, como era la del Perú que conquistaron los españoles.

Palabras clave: Perú prehispánico, Imperio inca, Listas de reyes, Historicismo, Antropología cognitiva, Estructuralismo, Tiempo lineal, Tiempo alterno, Orden social.

\section{SUMMARY}

The history of Prehispanic Peru is in a state of uncertainty ever since research from the perspective of cognitive anthropology (in the 1940s) and thereafter from that of structuralism (in the 1960s and 1970s) called into question the documentary value of the type of sources used until then to reconstruct such history. These sources are texts written after the inception of the Spanish conquest of Peru, in the $16^{\text {th }}$ century. In the 1940s, their contents started to be regarded and analyzed as mythological rather than historical. However, this revolutionary approach has not been accepted by a large number of scholars, who still assume that such texts can be dealt with as historical scurces in the commonest sense of the expression. The author believes that the key to overcoming this discrepancy lies in the native concepts of history, time and space and argues for a way out of the deadlock after critically examining the chief contributions of the two schools of researchers. In essence, it is a matter of finding the right articulation between structure and history in

RDTP, LIX, 1 (2004): 107-156 
a cultural tradition that is very much foreign to ours, as was that of Peru before the Spanish conquest.

Key words: Prehispanic Peru, Inca Empire, Lists of Kings, Historicism, Cognitive Anthropology, Structuralism, Linear Time, Alternate Time, Social Order.

En su Historia de los incas, el español Pedro Sarmiento de Gamboa cuenta de uno de sus reyes, Yáhuar-Huacca, que, siendo niño, fue raptado por el pueblo vecino de los ayarmacas. El padre de Yáhuar-Huacca era el rey Inca Rocca; su madre, la reina Mama Micay, quien era hija del señor del pueblo de Huayllacan, Soma Inca. El pueblo de Huayllacan estaba en el Antisuyu, en los confines orientales del mundo conocido. El desgraciado suceso ocurrió en una ocasión en que Yáhuar-Huacca se encontraba allí, en compañía de la familia de su madre. El señor de los ayarmacas, Tocay Cápac, estaba enojado con Inca Rocca y su esposa, ya que ésta le había sido prometida en matrimonio por Soma Inca, y quiso vengar la afrenta apoderándose del niño. Yáhuar-Huacca, al verse separado violentamente de sus familiares por manos enemigas, lloró lágrimas de sangre; y de ahí su nombre ("yawar-waqaq", "el que llora sangre" en quechua, su lengua nativa), con el que pasaría a la Historia. Hasta entonces, su nombre había sido "Titu Cusi Hualpa". Tocay Cápac, viendo la reacción de la criatura, se apiadó de él y no ordenó su muerte, pero le puso a trabajar de por vida como pastor de llamas. Sin embargo, un año después, hombres del pueblo de Anta, en el Chinchaysuyu (la parte septentrional del mundo), lograron rescatarlo y devolverlo a sus padres en Cusco, la capital del reino. Con el tiempo, el incidente sería olvidado y el rey Inca Rocca y Tocay Cápac harían las paces. Inca Rocca daría al señor de los ayarmacas una hija suya en matrimonio, al tiempo que Tocay Cápac daría una suya por mujer (y futura reina) al joven Yáhuar-Huacca. Una generación más tarde, siendo éste ya rey de los incas, el príncipe heredero, Viracocha, contraería matrimonio con una mujer del pueblo de Anta (Sarmiento de Gamboa 1988: 72-78, 80).

Yáhuar-Huacca ocupa generalmente el séptimo lugar (de un total de entre once y catorce) en las listas de reyes que nos han llegado de la historia del imperio inca ${ }^{1}$. Cuando se produjo la conquista española de la América andina, a partir del año 1532 de nuestra era, este imperio se extendía por buena

\footnotetext{
${ }^{1}$ Escribo el término "inca" con i minúscula cuando lo empleo como adjetivo, o como sustantivo cuando haga referencia al pueblo, etnia, nación o cultura andina del que surgió el imperio indígena con el que los españoles se toparon en América del Sur en el siglo Xvi. Emplearé el término "Inca" con I mayúscula cuando me refiera al título o dignidad real que encabezaba el orden político de este imperio.
} 
parte de lo que es hoy Perú, Bolivia, Ecuador, Argentina y Chile. Sus habitantes conocían este inmenso territorio con el nombre de Tawantinsuyu ("el país de las cuatro partes que forman un todo", en quechua). Abarcaba más de treinta y dos grados de latitud; pero para darnos una idea más exacta de sus dimensiones, debemos considerar que las enormes distancias de un lado a otro, y por medio de la cordillera de los Andes, había que cruzarlas a pie. No se conocían vehículos de tracción de ninguna clase. Tampoco animales de montura como son el caballo o el camello; tan sólo un animal de carga, la llama (lama glama).

Asimismo, no se conocía el uso del hierro; ni lo que nosotros entendemos por escritura, sino otros medios de registrar información, como pinturas, dibujos o nudos sobre cordeles de lana o algodón: los llamados kbipus. Aparte estaba, naturalmente, la transmisión oral. Por ello los incas, a diferencia de los mayas y otras antiguas civilizaciones, no dejaron memoria escrita alguna de cuál había sido su historia o cómo o por qué habían hecho cosas que a los conquistadores y colonos españoles tanto llamarían la atención, como llaman todavía hoy a visitantes y eruditos. Las memorias que nos han llegado sobre esta civilización y su historia las escribieron autores, en su mayoría españoles, cuando el imperio inca se estaba desmoronando o había desaparecido ya. Estos autores, como Sarmiento de Gamboa, tenían cada uno sus motivos para poner por escrito esa memoria; motivos que no eran siempre la curiosidad o el interés intelectual. Incluso cuando lo eran, su mundo no era el mismo que el nuestro.

Por si estos obstáculos a nuestro conocimiento no fueran suficientes, el desarrollo de la arqueología como fuente sucedánea o complementaria sólo ha tenido un desarrollo relativamente reciente para el periodo que nos interesa (ca. 1400-1532 d.C.), el último en el largo y complejo proceso de desarrollo cultural en la América andina antes del violento encuentro con la civilización occidental. Además, la arqueología tiene limitaciones ya de por sí, como es sabido. Es muy informativa sobre la cultura material de un pueblo y sobre la sustitución de esa cultura material por otra u otras; lo es menos sobre aspectos organizativos, incluidos los políticos y los económicos; y lo es poco o nada acerca de la religión, la cosmología y los valores sociales y morales.

Para todos estos temas de historia, instituciones y cultura no material dependemos de esos autores que escribieron después de 1532. La historia del rey Yáhuar-Huacca es un ejemplo de ello. Este rey - según cuentan Sarmiento y otros autores- había pertenecido a la dinastía de Hanan-Cusco, la cual había comenzado con el sexto rey, Inca Rocca, padre de YáhuarHuacca. Los cinco reyes anteriores habían pertenecido a una dinastía distinta, la de Hurin-Cusco. Los sucesores de Yáhuar-Huacca, hasta la llegada de los 
conquistadores españoles, todos pertenecerían a Hanan-Cusco. Uno de ellos (el $8^{\circ}$, el $9^{\circ}$ ó el $10^{\circ}$, según los distintos autores) fue el que fundó el imperio propiamente dicho: el primer rey que extendió y consolidó sus dominios, o extendió su influencia, más allá de los límites del valle de Cusco. Este punto de inflexión debió de ocurrir hacia el año 1400, según indica la arqueología de la zona (Bauer 1992: 46; D'Altroy 2002: 55). Hacia 1530, tras la muerte del $11^{\circ}$ ó $12^{\circ}$ soberano, según las listas —el Inca "Guayna Cápac"一, una devastadora guerra de sucesión protagonizada por dos de sus hijos, "Guáscar" y "Atahuallpa", facilitó el avance de los conquistadores españoles dos años más tarde. Encabezados por Francisco Pizarro, los invasores se alinearon primero con los vencidos en esa guerra (el bando de Guáscar) para doblegar a los vencedores (1532-1534); y después, se volvieron contra aquéllos cuando éstos ya no podían reaccionar. En 1536, el Inca Manco II, otro hijo de Guayna Cápac, a quien Pizarro había puesto en el trono, descubrió finalmente la estrategia de los conquistadores y se rebeló contra ellos. Pero su acción llegaba demasiado tarde y el levantamiento fracasó, aunque contribuyó a prolongar la resistencia inca. Las desavenencias y conflictos entre los españoles también contribuyeron a ello. El Estado incaico, finalmente reducido a los valles y junglas del sureste del Perú, aún conoció tres reyes más — Sayri Tupa, Titu Cusi Yupanqui y Tupa Amaru I- antes de ser destruido completamente en 1572.

Los primeros españoles en escribir sobre la historia general de los incas fueron Pedro de Cieza de León (1985) y Juan Díez de Betanzos (1987). Sus obras son relativamente tempranas - datan de la década de 1550 - si bien ninguna de las dos se publicó en su época ${ }^{2}$. La sucesión de reyes que mencionan, hasta la llegada de Pizarro y sus hombres, es la siguiente:

\section{Cieza de León Betanzos}

Dinastía Hurin:
1. Manco Cápac
1. Mango Cápac
2. Sinchi Roca
2. Cincherroca
3. Lloque Yupanqui
4. Mayta Cápac
3. Lloque Yupangue
5. Cápac Yupanqui
4. Cápac Yupangue
5. Mayta Cápac

\footnotetext{
${ }^{2}$ Cieza de León vio la publicación de la primera parte de su obra en 1553, un año antes de su muerte; pero la información sobre la historia de los incas está en la segunda parte, conocida como "El señorío de los incas", y ésta no se publicó por primera vez hasta el siglo XIX.
} 
Dinastía Hanan:
6. Inca Roca Inca
7. Inca Yupanqui
8. Viracocha Inca
9. Inca Yupanqui
10. Túpac Inca
11. Guayna Cápac
12. Guáscar
13. Atahuallpa

6. Yngarroca Ynga
7. Yáguar Guácac Ynga Yupangue
8. Vira Cocha Inga
9. Inga Yupangue Pachacuti Inga
10. Yamque Yupangue
11. Topaynga Yupangue
12. Guaina Cápac
13. Guáscar
14. Atagualpa

El primer rey, "Manco (o "Mango") Cápac", no había nacido en Cusco, sino en una localidad a unas siete leguas al sur: "Paccaritambo". Un buen día, él y sus hermanos (que eran dos, según Cieza; o tres, según Betanzos), junto con sus respectivas esposas, salieron de una cueva decididos a emigrar a una tierra mejor. La aventura les conduciría al final hasta el valle de Cusco, pero el viaje se hizo muy largo y estuvo lleno de peripecias. Poco después de partir de Paccaritambo, uno de los hermanos se reveló como demasiado fuerte y atrevido y los demás decidieron eliminarlo mediante un ardid. Le persuadieron de que volviera a la cueva de donde habían partido para, una vez dentro, taponarle la entrada y dejarle encerrado para siempre. Conseguido el objetivo, su esposa quedó como sirviente de Manco. Un segundo hermano tampoco llegaría a ver el valle de Cusco, pues se convirtió en piedra cuando el grupo se encontraba junto a un monte llamado "Guanacaure". Su esposa también pasó a ser sirviente de Manco. Finalmente, al llegar al valle, el grupo se presentó ante los lugareños como enviado por el sol y, poco después, fundó la ciudad. Manco adoptó entonces el título de "Cápac" como primer rey de los incas. En la versión de Betanzos, un tercer hermano y su esposa formaron parte del grupo que fundó Cusco; pero este hermano murió dos años después y su mujer, con quien no había tenido hijos, pasó entonces a servir, ella también, a Manco, como ya hacían las viudas de los otros dos hermanos. En su propia mujer, Manco engendró a Sinchi Roca y a otros hijos. A su muerte, Sinchi Roca sería el segundo rey de los incas (Betanzos 1987: 17-21; Cieza de León 1985: 41-45, 49-50).

\section{UNA HISTORIA DISCUTIDA}

El historiador más antiguo, Cieza de León, no estuvo entre los primeros conquistadores españoles; sin embargo, llegó a conocer bien el territorio andino y hablar con muchos de sus habitantes por medio de intérpretes. En Cusco se informó sobre la historia del imperio inca preguntando a varios notables del lugar, especialmente a un personaje llamado Cayu Túpac, quien descen- 
día del rey Guayna Cápac, mencionado por Cieza, como hemos visto, en el undécimo lugar de la sucesión (1985: 41). La obra de Cieza es admirable por varios motivos y entre ellos está que se ajusta a muchos de los requisitos que se exigen hoy de un historiador profesional, como así lo ha reconocido la gran mayoría de los especialistas. En ella describe su experiencia en el Perú y su método de trabajo; menciona a muchas de las fuentes que utilizó, comparó el contenido de éstas entre sí y las cotejó después con lo que sabían otros españoles que llevaban más tiempo que él en el país. Naturalmente, tenía sus prejuicios y se formó sus opiniones acerca del valor de la información que recibía; pero muchas de estas opiniones son claramente discernibles y, en no pocos casos de discrepancia con la información recibida, él mismo señala cuál era ésta.

Betanzos, por su parte, había residido en el Perú mucho más tiempo que Cieza antes de escribir su obra y, además, había aprendido la lengua oficial del imperio inca, el quechua, llegando a trabajar como intérprete para las autoridades españolas. Por si esto fuera poco, había contraído matrimonio con una mujer de la clase dirigente inca, "Cuxirimay Ocllo", quien había sido la esposa principal del Inca Atahuallpa, el último emperador hasta el inicio de la conquista española. Betanzos pudo recurrir así al testimonio de esta mujer y de sus parientes como fuentes principales para su historia, que por eso es más extensa en muchos capítulos que la de Cieza, especialmente los relativos a los últimos seis soberanos de su lista de sucesión (Martín Rubio 1987: xv). Pero Betanzos fue menos analítico y riguroso que Cieza en sus indagaciones y, además, fue parcial en todo lo que podía afectar a su esposa (y, a través de ella, a él mismo) en la sociedad colonial que se estaba formando, en la que interesaba mucho demostrar que se procedía de muy alta alcurnia -aunque ésta fuera indígena- para hacerse acreedor a exenciones fiscales y otros privilegios (Julien 2000: 17, 39-40).

En los reyes mencionados por ambos autores, a pesar de ser sus obras contemporáneas, habrá observado el lector diferencias entre las dos listas en cuanto al nombre, el número y el orden de los soberanos. Son diferencias que ilustran el problema epistemológico y metodológico al que he hecho referencia al principio, acerca de la naturaleza de las fuentes de información de que disponemos sobre las instituciones y la historia del imperio inca. Las discrepancias entre Cieza y Betanzos en cuanto a los nombres no son importantes en la mayoría de los casos; pues pueden deberse a meras diferencias de transcripción de las voces quechuas originales, como sirven de ejemplo los nombres de los dos primeros reyes: "Manco Cápac" y "Sinchi Roca" en la versión de Cieza y "Mango Cápac" y "Cincherroca" en la de Betanzos. Más importantes son otras discrepancias; como la que afecta al rey número siete, al que Cieza llama "Inca Yupanqui" y no "Yáguar Guácac Ynga 
Yupangue", como hace Betanzos (o un nombre que se le parezca), o "Titu Cusi Hualpa/Yáhuar-Huacca" como haría después Sarmiento. Cieza no cuenta la historia del rapto de este personaje por los ayarmacas cuando era niño, por lo que tal vez se trate de un rey distinto ${ }^{3}$. La misma clase de discrepancia ocurre con el rey número nueve, llamado también "Inca Yupanqui" por Cieza pero "Inga Yupangue Pachacuti Inga" por Betanzos, aunque en este caso es posible que se trate del mismo personaje, pues lo que cuenta Cieza de él pudiera entenderse como una síntesis de lo que transmite Betanzos.

Las divergencias en el orden y el número de los reyes son asimismo importantes. La sucesión de los reyes cuarto y. quinto está invertida en las dos versiones. Sin embargo, llama la atención que, salvo por esta discrepancia, la lista de los reyes burin sea idéntica en ambas; lo que extrañamente no ocurre con los reyes hanan, que sin embargo son presentados como los más recientes. Además del problema representado por el número siete, que acabo de mencionar, obsérvese que Betanzos inserta un rey hanan adicional entre los que Cieza llama "Inca Yupanqui" y "Túpac Inca": un tal "Yamque Yupangue", del que Betanzos cuenta que había sido el abuelo paterno de su esposa y que había reinado brevemente antes de abdicar en favor de su hermano menor, "Topaynga Yupangue" (el "Túpac Inca" de Cieza). Cieza no menciona para nada al tal "Yamque Yupangue"; pero un autor posterior, Martín de Murúa, sí que lo haría, aunque no para decir que fuera hermano de "Topaynga Yupangue" o que llegara a ser rey (Julien 2000: 40). Cabe interpretar entonces que Betanzos incluyó a "Yamque Yupanque" en la lista de reyes con el solo propósito de realzar la noble ascendencia de su esposa, como ha apuntado Julien (ibid.).

¿Pero significa esto que la lista de Cieza, de trece reyes, es entonces la verdadera, o la más fiable de las dos? Lamentablemente, no puede ser así. La versión de este autor para los reyes hanan presenta un artificio comparable al de Betanzos. Cuenta Cieza que el rey número ocho, "Viracocha Inca", fue sucedido por su hijo "Inca Urco", quien sin embargo no figura en su lista

\footnotetext{
${ }^{3}$ La identidad de Yáhuar-Huacca parece indisociablemente unida a esa historia. La expresión "lágrimas de sangre" puede haber sido originalmente española. En el Vocabulario de refranes de Gonzalo Correas [ca. 1637] (1924) se lee a propósito de ella: "Dícese encarecimiento: 'cuéstame lágrimas de sangre, llorar lágrimas de sangre; lágrimas de sangre me cuesta cada cosa que te pido'n. Al menos en la localidad de Llanes (Asturias) aún se usa el dicho "así llores lágrimas de sangre" o "aunque llores lágrimas de sangren; lo suele decir la madre a los hijos cuando piden caprichos con insistencia y la madre los ataja con esa frase. En el Diccionario de Autoridades se lee: "Llorar lágrymas de sangre. Phrase con que se explica un excessivo dolor, para cuyo sentimiento parece corta expressión la de las lágrymas ordinarias. Lat. sanguine flere. Debo esta observación a Antonio Cea.
} 
(como tampoco en la de Betanzos). La ascensión de este Inca Urco había tenido lugar en medio de una grave crisis política y militar: el naciente Estado inca había sido atacado por el vecino reino chanca, al noroeste, y el rey "Viracocha Inca" había decidido renunciar al trono en favor de su hijo Urco. Sin embargo, el nuevo rey no se reveló lo bastante capaz como para organizar una resistencia efectiva al ejército invasor y entonces una importante facción de la nobleza inca decidió rebelarse, apartarlo del trono y poner en su lugar a su hermano "Inca Yupanqui", quien había dado muestras de mayor valor y resolución. Así que es este "Inca Yupanqui", el segundo de este nombre, quien figura como noveno rey en la lista hanan de Cieza. El autor explica la ausencia en ella de "Inca Urco" de esta manera:

Los orejones [la nobleza inca], y aún todos los demás naturales destas provincias, se reyeron [rieron] de los hechos deste Inca Urco. Por sus poquedades quieren que no goce de que digan que alcanzó la dignidad del reino y así vemos que en la cuenta que de los quipos [kbipus] y romances tienen de los reyes que reinaron en el Cuzco callan éste, lo cual yo no haré, pues al fin, mal o bien, con vicios o virtudes, gobernó y mandó el reino algunos días (Cieza de León 1985: 137).

En otras palabras, Cieza optó por respetar lo que le habían dicho sus informantes, al menos en cuanto a la sucesión de los reyes; y esta versión, que no era neutral — pues tomaba partido por "Inca Yupanqui"-, estaba registrada en "quipos y romances". No obstante, el español hizo suya tal información sólo en parte, pues él mismo advierte de que también recurrió a su propio criterio para valorar lo que le habían transmitido y componer su propia historia: un criterio que era distinto del de sus fuentes. Y que es asimismo distinto del criterio del investigador contemporáneo. Los conocimientos, creencias, conceptos y valores de Cieza eran los de la Castilla cristiana y caballeresca de la primera mitad del siglo xvI.

¿Cómo salvar entonces el doble filtro representado por las versiones interesadas de los informantes incas y por la diferente lengua y cultura de sus medios de transmisión, los textos españoles (por no hablar de las ediciones defectuosas de estos textos), cuando no se conservan las fuentes originales? Hasta la década de 1940, los especialistas se afanaron, básicamente, por buscar y dar a conocer el mayor número de textos posible con el fin de analizarlos críticamente, cotejarlos entre sí y poder llegar a una sola narración razonable y coherente de la historia y las instituciones del imperio inca. A esta tradición de crítica histórica pertenecen los brillantes trabajos de Clements R. Markham (1910), José de la Riva-Agüero (1965 [1910]), Louis Baudin (1928), Philip A. Means (1931: 205-357) y John H. Rowe (1945, 1946).

Fue en la década de 1940 cuando se empezó a pensar que esa historia transmitida por manos y mentes ajenas, y en ocasiones mucho después de 
los hechos - como la historia de Yáhuar-Huacca-, podía no ser historia realmente, sino mitología, y como tal debía ser tratada. Si eran mitos, esas narraciones transmitidas por los españoles debían entenderse, antes de nada, como respuestas a preguntas que los incas y otros pueblos andinos se hubieran hecho sobre la condición humana y el universo, sobre el origen y razón de ser de sus formas de vida, orden político e instituciones, así como sobre las relaciones sociales internas y externas que conocían. Un indicador muy elocuente de que una sociedad acepta como satisfactorias las respuestas intemporales que los mitos ofrecen es que sus miembros los aprenden fácilmente de memoria y después corren de boca en boca y de generación en generación. Los hechos que se relatan en estas narraciones, si bien pueden aparecer en orden cronológico, forman parte de un discurso articulado que pertenece siempre al presente, al cual sirven como modelo o pauta para la acción. Por tanto, no son hechos propiamente, sino piezas de un conjunto, componentes de una estructura discursiva, partes de un mensaje; están relacionadas entre sí de alguna manera, pero siempre en el presente. Sólo pasan a pertenecer al pasado cuando la historia deja de contarse; esto es, cuando el mito cae en desuso y se olvida.

En el texto sobre Yáhuar-Huacca, por seguir con este ejemplo, un lector crítico podría darse cuenta, sin muchas dificultades, de que comunica algo más de lo que se lee a primera vista y entendió Sarmiento. Pudiera llamarle la atención, en primer lugar, que Tocay Cápac, el señor de los ayarmacas, hubiera querido vengarse de Soma Inca apoderándose del hijo de Inca Rocca y de Mama Micay. Más justo sería que hubiese dirigido su cólera contra Soma Inca directamente; lo cual sugiere que, más que la venganza, lo que había animado a Tocay Cápac sería su deseo de apoderarse de un hijo que consideraba suyo.

Otro dato que pudiera dar que pensar es que fueran terceros, hombres del pueblo de Anta, quienes rescataron al niño; hombres que, además, no se vieron recompensados hasta una generación más tarde y sólo indirectamente, mediante el matrimonio de una de las mujeres del pueblo con el príncipe inca, el heredero de Yáhuar-Huacca. Esta parte de la historia da a entender una relación triangular: hay algo que unía a los incas con el pueblo de Anta con anterioridad al suceso del rapto y que queda oculto en el texto.

Los nombres de Soma Inca y de Tocay Cápac, por otro lado, indican realeza o nobleza; lo que cabe interpretar como que ambos personajes tienen en la historia el mismo status, o parecido, al de Inca Rocca. Unidos esos dos nombres a los de "Antisuyu" y "Chinchaysuyu", que significan grosso modo "este" y "norte", respectivamente, parece que estamos ante una relación de lugares o pueblos conectados con las direcciones cardinales, o partes del mundo conocido, mediante alianzas matrimoniales. El lector podría entonces 
preguntarse si Sarmiento ofrece asimismo información sobre los matrimonios de otros reyes, de modo que pueda saberse si las alianzas entre los incas y sus vecinos afectaban también a las demás direcciones. Así, si dice que el hijo de Yáhuar-Huacca se casaría con una mujer de Anta, que estaba en el norte, ¿dice también el autor español, en alguna otra parte de su obra, de dónde era la mujer con quien se casaría su nieto? La respuesta es afirmativa: Sarmiento indica (1988: 100) que esta mujer nacería en el pueblo de Choco, que estaba en el "Cuntisuyu", el oeste.

Por consiguiente, un cierto orden, y ya no sólo una narración, empieza a tomar forma. Para completarla, sólo falta ya una de las cuatro partes en que se dividía el Tawantinsuyu: el "Collasuyu" o sur. Sarmiento señala en la historia que Yáhuar-Huacca se casó con una princesa de los ayarmacas; no indica dónde residía este pueblo, pero sabemos por otros autores, como el Inca Garcilaso (1991: 51), que había ayarmacas en esa dirección. Resulta entonces una red de alianzas matrimoniales exhaustiva de las cuatro partes en que se dividía el mundo conocido, como advirtiera el antropólogo holandés R. Tom Zuidema (1964: 133-153); una red reproducible tras el mismo número de generaciones y en la que las cuatro partes del Tawantinsuyu actuaban como clases matrimoniales. Véase el diagrama adjunto, que representa no sólo un complicado, aunque estable, orden diplomático entre pueblos vecinos, sino también que éstos, incluidos los incas, reconocían la descendencia por línea

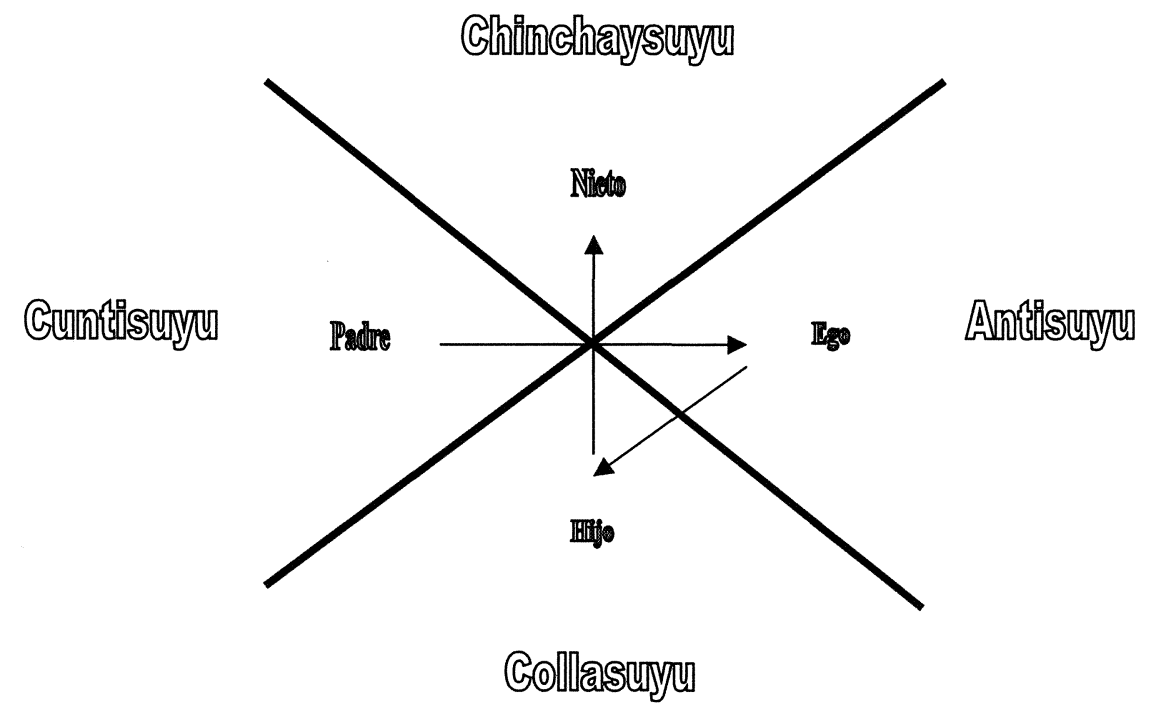

DiAGRAMA 1.-Alianzas matrimoniales en la genealogía del Inca Yáhuar-Huacca narrada por Sarmiento de Gamboa. 
femenina y no (o no sólo) por la masculina. Al menos el rey no heredaba de su padre su pertenencia a una clase matrimonial, sino de su madre.

La sospecha de que las narraciones españolas sobre los incas, como la historia de Yáhuar-Huacca, podían no tener validez histórica en nuestro sentido de la expresión -aunque los personajes mencionados pudieran haber existido- no era del todo nueva en la década de 1940: ya había sido expuesta en los siglos XVI y XVII por muchos de los autores que pusieron por escrito esa información, incluido Sarmiento, aunque sólo en cuanto a los orígenes de los incas y la consagración de Manco Cápac como primer rey en Cusco, historias que los españoles calificaron de "fábulas". La crítica contemporánea, desde el siglo XIX, haría suya esta valoración, pero asimismo la de que sí había sido historia lo sucedido con los demás reyes hasta la conquista española.

El primer estudioso que puso esta generalizada opinión en entredicho, y sistemáticamente, argumentando sobre el carácter propiamente no histórico de los textos que recogen el conjunto del acontecer incaico - no sólo la narración de los orígenes y el primer rey-, fue el argentino José Imbelloni (1941, 1944, 1946), quien enfocó el problema desde una antropología cognitiva y con una metodología comparable a la que en el siglo XIX había empleado la crítica filológica alemana sobre la historia temprana de Roma ${ }^{4}$. Imbelloni interpretó las listas de reyes contenidas en algunas de las obras de los españoles como textos que ocultaban una forma indígena de codificar un concepto cíclico del tiempo.

Una década después, desde la crítica historiográfica, el sueco Sverker Arnoldsson advertía contra una posible proyección a la historia de los incas de conceptos de la Edad Media y el Renacimiento originados en la Antigüedad clásica, como la Edad de Oro o su antítesis, el salvajismo primigenio; o como el concepto de Héroe Civilizador (Arnoldsson 1965). En los años sesenta, el también sueco Åke Wedin fue aún más lejos: planteó que eran del todo inútiles los intentos por reconstruir la historia de los incas anterior a 1532. Según él, tales intentos estaban condenados a ser siempre especulativos, al no existir un solo documento indígena que fuera totalmente independiente de los textos españoles o libre de las transformaciones acaecidas en el Perú después de 1532. En puridad metodológica —escribió-, los interesados sólo podrían aspirar a una reconstrucción de ciertas instituciones incaicas, pues éstas continuaron en funcionamiento - mal que bien - unas décadas más, mientras se desarrollaba la conquista española (Wedin 1963, 1965, 1966).

${ }^{4}$ El investigador argentino contaba con el precedente del alemán Max Uhle (1912: $313,341-346)$, quien desde una perspectiva evolucionista había apuntado que toda la tradición sobre los incas anterior a su periodo imperial carecía de valor histórico. Pero Uhle apenas llegó a profundizar en este planteamiento, a diferencia del argentino. 
Pero la principal y más conocida aportación desde esta nueva perspectiva provendría de la escuela estructuralista de Claude Lévi-Strauss, cuyo representante más notable en el campo de la antropología andinista ha sido el ya mencionado R. T. Zuidema. Desde 1964 y mediante numerosos trabajos (v. g., 1964, 1973, 1977, 1989a, 1989b, 1989c, 1990), este investigador ha hecho un gran esfuerzo por interpretar en clave mitológica, como Imbelloni, las narraciones sobre los incas, en su caso a la luz de otros textos que tratan abiertamente de sus ritos y ceremonias, sus instituciones sociales y políticas y sus creencias y cosmología, incluida su concepción del tiempo y del espacio. Zuidema también se ha servido de etnografías de comunidades indígenas contemporáneas en Perú y Bolivia, así como de estudios estructuralistas de mitos y estructura social en otras partes de América y del mundo.

Las investigaciones de Imbelloni, Arnoldsson y Wedin, pero especialmente los primeros trabajos de Zuidema y los de otros estructuralistas - como Nathan Wachtel (1966, 1971a, 1971b), Juan M. Ossio (1973, 1977), Pierre Duviols (1980a, 1980b) y Jan Szemiński (1982-1984)—, ocasionaron un gran desconcierto entre los demás estudiosos del imperio incaico. Algunos de ellos reaccionaron hasta con crispación, como fue el caso de Burr C. Brundage, autor de uno de los últimos productos de la historiografía tradicional (1963). Brundage calificó el planteamiento de Zuidema de nada menos que un "ignorant and malicious attack [...] delivered upon the discipline of history" (1966: 231).

Desde de los años setenta, la reacción ha sido más constructiva, pero sin llegar a poner fin al desencuentro con la perspectiva estructuralista. El impacto de ésta en la bibliografía ha sido de tres tipos. En primer lugar figura el impacto indirecto y, en la mayoría de estos estudios, probablemente sobrevenido: así como las contribuciones estructuralistas ofrecían (y ofrecen) un retrato atemporal de la cultura inca, se han hecho en las últimas décadas investigaciones cuyos autores, aunque ajenos al estructuralismo, han evitado al máximo las consideraciones históricas. El estructuralismo ha podido reforzar en ellos un interés por lo sincrónico que es muy anterior a 1960: como el mostrado por la organización imperial, o por ciertas instituciones incaicas, o por estudios regionales con la ayuda de la arqueología y los papeles de la administración española. Entre estos trabajos cabe destacar los de John Murra (1975a, 1978), Waldemar Espinoza Soriano (v. g., 1969, 1981), Patricia Netherly (1984), Terence D'Altroy (v. g., D'Altroy y Hastorf 1984, D'Altroy y Earle 1985) y Frank Salomon (1986).

En otros estudios, el impacto ha sido de refracción: sus autores no han eludido el cuestionado tema de la historia de los incas y hasta han ofrecido interpretaciones nuevas de los textos que la contienen, muchas de ellas desde el marxismo; pero estos investigadores han incorporado pocas o ninguna de 
las aportaciones estructuralistas. Es el caso de Richard Schaedel (1978), Geoffrey Conrad y Arthur Demarest (1984) y Thomas Patterson (1991), entre otros.

Del tercer tipo son las obras en las que el impacto ha sido directo, pero en las que también se observa una suerte de retroalimentación negativa: sus autores, notablemente John Rowe (1967, 1985a, 1993-94), María Rostworowski de Díez Canseco (1983, 1988), Martti Pärssinen (1992), Juha Hiltunen (1999) y Catherine Julien (2000), se han tomado en serio las aportaciones estructuralistas y han examinado críticamente algunas de ellas, pero ofreciendo como alternativa nuevas interpretaciones de los textos que son coherentes con lo fundamental de las conclusiones del historicismo anterior a $1960^{5}$.

Las razones de que el efecto producido por los trabajos de Zuidema y otros estructuralistas haya sido, en el mejor de los casos, tan oblícuo y parcial, creo que han sido principalmente tres: 1) el posicionamiento radicalmente ahistórico de esta nueva perspectiva; 2) el carácter innecesariamente abstruso y extrañamente cambiante de algunas de las argumentaciones ofrecidas, notoriamente las de Zuidema, y 3) los excesos interpretativos cometidos en ocasiones en el análisis de los textos, de nuevo por Zuidema especialmente. Son rasgos todos ellos lamentables, pues la obra del estudioso holandés y la de otros estructuralistas, como antes la de Imbelloni, es valiosa en gran parte y debiera por ello merecer un mayor aprovechamiento entre los demás investigadores. La obra de éstos es vulnerable por esta carencia.

El conocimiento de la historia de los incas sigue por ello adoleciendo hoy de la crisis epistemológica y metodológica abierta en los años cuarenta y, sobre todo, en los sesenta. El efecto de esta crisis, para el lector interesado $\mathrm{y}$ ajeno, es un turbador estado de incertidumbre que ha venido a añadirse al derivado de una larga controversia acerca de la economía política inca, sobre la que he tratado en otro trabajo (1998). Hasta ahora no ha habido un intento serio y en profundidad por superar esta situación y lograr un encuentro razonable entre lo más valioso de ambas líneas de investigación, la estructuralista y la tradicional o historicista. Mi propósito en este artículo es tan sólo

${ }^{5}$ Utilizo el término "historicismo" en el sentido que le diera Mircea Eliade (1999: 139-149) y no en el que tenía para Karl Popper (1991). Me refiero a la historia entendida como una sucesión continua, singular e irreversible de acontecimientos, sin sentido trascendente para el presente y el futuro más allá de sus efectos comprobables: "lo que sucede está 'bien' justamente porque sucedión (ibid.: 40; énfasis de Eliade). Además de contrapuesto al de "estructuraw, este concepto de la historia se opone al presentista (el pasado visto teleológicamente desde la óptica del presente), así como a lo que Popper entendió por ahistoricismon: una filosofía de la historia y un método para estudiarla consistente en buscar e identificar en el pasado las leyes del devenir humano que determinarán el futuro de la sociedad. 
el de tratar de exponer las bases para un deseable contrapunto, examinando críticamente las principales aportaciones de ambas corrientes y aprovechando lo que me parece más valioso de ellas. Parto del convencimiento de que es posible reconstruir y hacer inteligible para nosotros, con independencia de la ayuda de la arqueología, la historia del imperio inca; no de toda ella, pero sí de la parte final: de las décadas anteriores al inicio de la conquista española y desde este punto hasta la total desaparición del poder político incaico en 1572. Es una historia que, naturalmente, debe comprenderse teniendo en cuenta el sentido que tuvieron los hechos para sus protagonistas, dada la cultura en que estaban inmersos; lo que incluye los conceptos que tenían de Historia, Tiempo y Espacio. Es aquí donde son relevantes muchas de las contribuciones de Imbelloni y de los estructuralistas como Zuidema. Pero no por ello cabe entender que no fue historia (en el sentido común que tiene esta palabra hoy en castellano) lo que vivieron y trajo consigo la conquista española $-\mathrm{y}$ que trataron de salvar del olvido los autores del siglo XVI-, como han defendido los críticos del estructuralismo.

\section{LOS CINCO SOLES}

Imbelloni inició la ruptura con la historiografía tradicional analizando textos sobre el Perú prehispánico que, aunque tardíos (de finales del siglo XVI a mediados del XVII), eran en buena parte de contenido indígena: los de Felipe Guaman Poma de Ayala, Buenaventura de Salinas y Córdoba, Blas Valera, Anello Oliva y, sobre todo, Fernando Montesinos. La obra de Montesinos, escrita en la década de 1640 y nunca acabada, se había publicado parcialmente por primera vez en francés en la primera mitad del siglo XIX. Las primeras ediciones en español, a cargo de Vicente Fidel López y Marcos Jiménez de la Espada, habían aparecido en 1869-70 y 1882 (en Buenos Aires y Madrid, respectivamente), dando lugar entonces a un gran interés en la obra; hasta el punto de convertirse en principal fuente de referencia hasta bien entrado el siglo $\mathrm{xx}^{6}$.

En clara contraposición con otros textos ya conocidos, el de Montesinos ofrecía la particularidad de narrar una sucesión de hasta 93 reyes peruanos que habían precedido a los Incas, a los que el autor añadía la de 11 Incas

\footnotetext{
${ }^{6}$ La edición de López de 1869-70 se había basado en la copia defectuosa, del siglo XVIII, de un manuscrito perdido de la obra de Montesinos; esta copia es la que había sido traducida al francés treinta años antes (Jiménez de la Espada 1882: vii-xiv; Porras Barrenechea 1986: 492; Hiltunen 1999: 58). Por el contrario, la edición de Jiménez de la Espada, de 1882, derivaba de un texto conocido por Montesinos y listo para su publicación en su época (Jiménez de la Espada, ibid: xiv-xix), razón por la cual esta edición ha sido la más utilizada y es la que seguiré yo en este ensayo.
} 
hasta el inicio de la conquista española. Si el periodo incaico había durado entre cuatrocientos y quinientos años, como habían escrito ya otros autores, como Polo de Ondegardo - a quien Montesinos citaba (1882: 46)- y Antonio Vázquez de Espinosa (1969: 391), la historia completa de los reyes prehispánicos abarcaría unos cuatro mil quinientos años en total.

En su momento no extrañó mucho que los nombres y los hechos de tal número de soberanos (104 entre Incas y pre-Incas) pudieran transmitirse a lo largo de generaciones y finalmente ponerse por escrito por un autor tan tardío como Montesinos y no por algún otro español de los primeros tiempos, tan interesado o más que él en la historia antigua del Perú. No obstante, hay que tener en cuenta que la difusión de la historia de Montesinos a partir de 1870, y especialmente de 1882, tuvo lugar en una época en que empezaban a conocerse, a través de la arqueología, algunas de las culturas andinas preincaicas, especialmente la de Tiahuanaco (ca. 300-1000 d. C.; Kolata 1993: 85-86); por lo que no tardó en aceptarse la idea de que los 93 reyes pre-Incas que el español mencionaba, encajaban con el gran desarrollo que había tenido la civilización en los Andes durante miles de años, tal como sugerían los estudios arqueológicos.

Tres de los investigadores que entendieron así esa larga lista de reyes -Riva-Agüero (1965: 68-79), Markham (1920: 9-14) y Means (1920: xxi-xxv, xxxix) - razonaron que el número real de soberanos debió de haber sido menor, ya que Montesinos contaba muy pocas cosas, apenas el nombre, de la mayoría de los reyes y mucho de lo que decía de los demás se leía en otras obras en referencia a los Incas. Para Imbelloni, se trataba de un caso claro de transposición: de relleno artificioso, a base de duplicaciones o segmentaciones de material narrativo, de una estructura conceptual original.

$\mathrm{Al}$ investigador argentino le intrigaron también otros aspectos del texto del español en los que que sus predecesores no se habían detenido lo suficiente; por ejemplo, que ocho de los 104 reyes mencionados llevaran el apelativo "Pachacuti" - como el noveno Inca mencionado por Betanzos- y que la mayoría de tales ocho monarcas hubiera accedido al trono a intervalos regulares. La explicación de esta regularidad la daba el propio Montesinos al hablar del soberano "Ayay Manco I", el rey número 35, del que escribió (1882: 68-69) que bajo su reinado se había hecho una reforma del calendario, de acuerdo con la cual a los años se les había agrupado por décadas y a éstas por siglos, hasta completar periodos de diez siglos, que llamaron "soles". A la mitad de un "sol", o sea 500 años, llamaron "pachacuti".

Extrañamente, Montesinos no explicaba cómo esta reforma se hubiera hecho cuando ya habían reinado en el Perú cuatro monarcas apellidados "Pachacuti" y no antes de que lo hiciera nadie con ese nombre. Bajo el reinado del quinto Pachacuti — señaló (ibid: 73 ) — se cumplirían 2.500 años 
desde el Diluvio Universal mencionado en la Biblia y, por tanto, de la fecha más remota posible de la llegada del primer ser humano a las Indias Occidentales. Como desde la Creación del Mundo hasta el Diluvio hubieran transcurrido 1.000 años —de nuevo según Montesinos-, la vida de ese rey vendría a coincidir con la mitad del tercer "sol" o edad en la historia del Perú y, a la vez, con la mitad del cuarto "sol" desde la Creación del Mundo.

Imbelloni llamó asimismo la atención sobre que los reinados de muchos de los reyes Pachacuti coincidieran con grandes cambios o calamidades en el país. Como sucedió, por ejemplo, bajo el reinado del último soberano antes de los incas, "Inti Maita Cápac", el rey número 93:

A los veintisiete años del reinado déste se cumplieron cuatro mil años después del Diluvio y el quinto sol de la creación del mundo; y por eso se llamó Pachacuti, octavo deste nombre, en cuyo tiempo acabó el vicio de corromper las buenas costumbres, y ya la sodomía era pecado político. No había obediencia; vivían los hombres en behetría [sin reconocer autoridad señorial] y como bestias, lo cual duró algunos años, hasta que los Ingas se introdujeron en esta monarquía (Montesinos 1882: 90) (añadido mío).

De hecho, etimológicamente el término quechua pachakuti no significa propiamente un periodo de 500 años, sino un cambio abrupto (o vuelco) violento en el tiempo, así como en el espacio o mundo conocido. El sustantivo pacha tiene ambas acepciones: tiempo y espacio. Kuti significa "vez" o turno, así como "revés"; es también la raíz de los verbos kutiy y kutiriy, "regresar, retornar. Dar media vuelta. Reponerse" (Lara 1997: 109). Los reyes Pachacuti, por consiguiente, serían todos aquellos en cuyos reinados se hubieran producido grandes transformaciones o acontecimientos que hicieran época, como los descritos bajo "Inti Maita Cápac": cada 500 años, según la reforma del calendario mencionada, y especialmente cada 1.000 años, que es cuando el pachakuti coincidía con el cambio de "sol" o edad. Como la época de los Incas se desarrolló durante el quinto sol, que había empezado en el año 4.000 desde el Diluvio, y el total de la historia del Perú prehispánico había durado unos 4.500 años, ésta habría conocido entonces hasta nueve reyes Pachacuti. El noveno habría sido uno de los once Incas de la lista: teóricamente el último, el Inca Atahuallpa, bajo cuyo reinado se había producido la destructiva invasión española.

$\mathrm{Y}$, en efecto, Montesinos, como ya he señalado, enumeraba no más que ocho reyes Pachacuti entre los 104 soberanos hasta la conquista española. No obstante, en la época final o incaica destacaba especialmente algunos sucesos: los acontecidos en el tiempo del séptimo Inca y rey número 100 de la lista, "Inga Huira Cocha", asimismo llamado "Túpac Yupanqui". Decía Montesinos de él que "entre los indios fue tenido por más que hombre" y 
que, bajo su reinado, repleto de acontecimientos notables, se había completado el sexto "sol" desde el Diluvio (ibid.: caps. XXIII a XXVI); lo cual es una clara contradicción con lo afirmado anteriormente acerca de la duración de los "soles" y "pachacutis" y la correlación de estas unidades de tiempo con la lista de soberanos y con la época inca. Imbelloni razonó acertadamente que Montesinos se habría hecho aquí eco de un cómputo distinto, aplicado específicamente a los Incas, sin advertir la incongruencia con: 1) la cuenta de los 4.500 años para toda la historia peruana prehispánica y 2) la afirmación de que los once Incas se habían sucedido a partir del año 4.000. El segundo cómputo habría asignado un pachakuti a un Inca que había reinado varias generaciones antes de la llegada de los españoles. En la versión de Montesinos, este rey habría sido el llamado por él "Inga Huira Cocha" y "Túpac Yupanqui", el Inca número 7.

El investigador argentino explicaba de paso por qué en las listas de Incas de otros autores, como Betanzos o Sarmiento, sí aparece el apelativo "Pachacuti" en el nombre de un rey que no es el último y al que se le asignan los cruciales logros en la historia de los incas que Montesinos atribuye a "Inga Huira Cocha" o "Túpac Yupanqui". Tal Inca Pachacuti es justamente el rey número 9 en esas listas: lo que cabe interpretar como que este número de orden no significaría que este rey hubiera sido realmente el noveno en la historia de los incas, sino que el reinado de un personaje identificado así servía para señalar el noveno pachakuti en una historia periódica de al menos 4.500 años hasta la conquista española, como también sugiere el anónimo autor - probablemente el mestizo Blas Valera, una de las principales fuentes de Montesinos- de una Relación de las costumbres antiguas de los naturales del Pirú (Anónimo 1992: 80, 85).

Tratándose la voz pachakuti de un término que hacía referencia, en primera instancia, a un cambio de época y de mundo, y no al nombre de una persona, se explicaría igualmente entonces por qué el apelativo "Pachacuti" no aparece en varias listas de Incas, como la de Cieza de León; o por qué los notables hechos que Betanzos, Sarmiento y otros autores atribuyen al número 9, denominado "Inca Pachacuti" (entre tales hechos, el comienzo de la fase propiamente imperial en la historia de los incas), son atribuidos por otros autores a otros reyes en sus propias listas, generalmente al que aparece como antecesor o sucesor suyo en aquellas otras en que sí es mencionado. Por ejemplo, Montesinos, como hemos visto, asigna tales logros memorables a "Inga Huira Cocha", también llamado "Túpac Yupanqui", como su hijo y heredero: dos nombres de reyes que corresponden a los Incas 8 y 11 en la lista de Betanzos y al 8 y al 10 en la de Sarmiento, respectivamente. Esta discrepancia le hizo pensar a Imbelloni que lo que importaba de la información indígena transmitida a españoles como Montesinos o a sus fuentes no 
era tanto la identidad histórica de tal o cual soberano, cuanto los hechos que definían el cambio de época y de sociedad en una estructura cíclica de la manera de concebir el paso del tiempo y, por extensión, de la historia; tal cambio se llamaba pachakuti y por eso en algunas listas lleva el sobrenombre de "Pachacuti" el soberano al que, por su orden en esa estructura, correspondía asignar tales sucesos. En otras versiones, ningún soberano aparece con tal apelativo, pero sí los hechos que definen el cambio, que entonces se atribuyen al rey nombrado en el orden correspondiente.

Imbelloni concluyó que, de acuerdo con esta cosmología andina oculta sobre el tiempo y la historia —compuesta de ciclos de 1, 10, 100, 500 y 1.000 años-, habría habido en el documento más original entre las fuentes de Montesinos (esto es, el menos contaminado por la cultura cristiana) una sucesión de no más de 90 reyes para 4.500 años; en otras palabras, tantos reyes como casillas en una estructura cosmológica de 10 soberanos por cada quinientos años y 20 por cada mil. Con estos 90 reyes aparecerían, además, 9 anotaciones de pachakuti para cada fin y comienzo de un ciclo de 500 años, anotaciones que con el tiempo se personificarían asimismo como nombres de reyes. Los once Incas serían la última serie de diez soberanos más un pachakuti, que rellenarían el último tramo de 500 años de la estructura.

Así, con independencia de la información sobre los últimos Incas obtenida del recuerdo personal de quienes les habían conocido, la "historia" del Perú prehispánico según Montesinos, como según Valera y otros autores, no sería en realidad sino una forma de racionalizar el pasado en la cultura aborigen: es decir, un producto intelectual, derivado de un "terror a la historia", a la historia lineal y sin sentido, de la que escribiría Mircea Eliade algunos años más tarde tras analizar comparativamente el mito del eterno retorno en diversas civilizaciones, aunque sin incluir la andina (Eliade 1999: 56-57, 129-149).

Buenaventura de Salinas y Córdoba (en Imbelloni 1944) y el indígena Felipe Guaman Poma de Ayala (1980: 49-79) habrían recogido una variante de la misma forma de racionalización: una división del pasado preincaico no en 80 u 88 reyes, sino en 4 "generaciones" o "edades" llamadas "Uari Uira Cocha runa", "Uari runa", "Purun runa" y "Auca runa", por este orden. Salinas personificó estas "generaciones" —claro trasunto de los "soles" de Montesinosen otros tantos "caudillos" o "capitanes" con esos mismos nombres. Cada "generación", según él, había representado un grado de progreso en lo material y organizativo, aunque también de pérdida de inocencia y caída en la idolatría; hasta llegar a la edad de los Incas, la más ordenada y sobresaliente, y a la vez la más alejada de la virtud original, como ilustraba el hecho de que los Incas - se decía- hubieran recurrido al engaño y la fuerza para hacerse con el gobierno del Perú. 
Aunque Salinas y Guaman Poma de Ayala diferían en cuanto a la duración que había tenido cada una de esas cinco edades, lo significativo de su esquema para Imbelloni era que albergaba el mismo concepto sobre el tiempo y la historia de la estructura de Montesinos: un concepto periódico donde aparece marcada la contraposición entre el tiempo de los Incas (representando al presente) y un pasado, éste dividido en cuatro partes. Imbelloni encontró paralelismos de esta contraposición entre otros pueblos indígenas americanos, notablemente entre los aztecas y los mayas quichés. La división del tiempo en cuatro partes se correspondía con la misma forma de división en el espacio; v. g., los cuatro puntos cardinales. En el caso del imperio inca, correspondía a las cuatro regiones en que se dividía el país (de ahí su nombre: Tawantinsuyu) o a los cuatro caminos que salían de la capital en esas direcciones. Por ello, la unidad de mil años o "sol", el total de cinco "soles" y los cuatro pachakuti para señalar el paso de un "sol" a otro habrían sido los componentes fundamentales en la estructura cosmológica transmitida por Montesinos.

A esa estructura original se le habría añadido después el concepto de pachakuti cada 500 años, por efecto de una subdivisión en dos mitades o épocas del "sol" o edad de 1.000 años. Las dos dinastías de los Incas, hanan y burin, habrían sido fruto de una operación semejante. En principio, explicó Imbelloni, sólo habría habido una dinastía; la subdivisión habría surgido de una duplicación de la sucesión de los reyes, obtenida a base de transponer acontecimientos de unos monarcas originales en otros creados ad hoc, como había hecho Montesinos, o sus fuentes, para obtener el total de los 80 reyes preincaicos.

Como el resto de la argumentación del gran investigador argentino, fue éste un planteamiento nuevo y sugerente. No obstante, a la luz de las investigaciones posteriores, puede considerarse hoy como el menos acabado y persuasivo. Imbelloni no llegó a entender o valorar del todo el significado que tenía el principio dual (aparte de la cuadripartición) en la cosmología andina, tal vez por desconocer o no dar importancia al dualismo observado en la estructura social y política de muchas etnias en los Andes, tanto en los siglos XVI y XVII como en la época contemporánea. Habría que esperar a la obra de Zuidema (1964: 126-128; 1973: 8-11) y de Duviols (1980a) para obtener una argumentación más convincente sobre las dos dinastías incas.

\section{LAS DIEZ FASES}

Tal vez por ser de menor relevancia para su argumentación, Imbelloni tampoco valoró suficientemente la quinquepartición y la división decimal que también estaban implícitas en la cosmología transmitida por Montesinos. Si 
las cuatro "generaciones" o "edades" preincaicas eran la proyección en el tiempo de una cuadripartición en el espacio -como había advertido el antropólogo argentino-, el total de cinco edades "históricas" para el Perú anterior a los españoles, incluida la de los incas, correspondería en el tiempo a una quinquepartición política en la sociedad, como apuntaría Zuidema (1964: 218220) y luego mostrarían Wachtel (1971a) y Ossio $(1973,1977)$ analizando más pormenorizadamente la obra de Guaman Poma de Ayala. Esta quinquepartición integraba a las cuatro partes o suyu del Imperio (Cuntisuyu, Antisuyu, Collasuyu y Chinchaysuyu, en este orden jerárquico de importancia, de menor a mayor) junto a una quinta región que era la que tenía la preeminencia sobre las demás: el mismo centro político del conjunto, Cusco, donde el Inca tenía su corte (véase el diagrama 2). En la correlación espacio-tiempo, esta estructura política quinquepartita, con el diferente rango de sus componentes, adquiría una dimensión temporal en el esquema de las cinco edades prehispánicas y sus respectivos valores; así, el mayor rango de Cusco sobre cada de una de las cuatro regiones del Tawantinsuyu se correspondía con el valor concedido a la edad de los incas como edad presente en contraposición con las cuatro edades "históricas" del pasado, menos desarrolladas material e institucionalmente.

El estudio más profundo de la obra de Guaman Poma de Ayala revelaría asimismo que tal estructura quinquepartita de espacio-tiempo era entendida

\section{Cholnehangsungu}

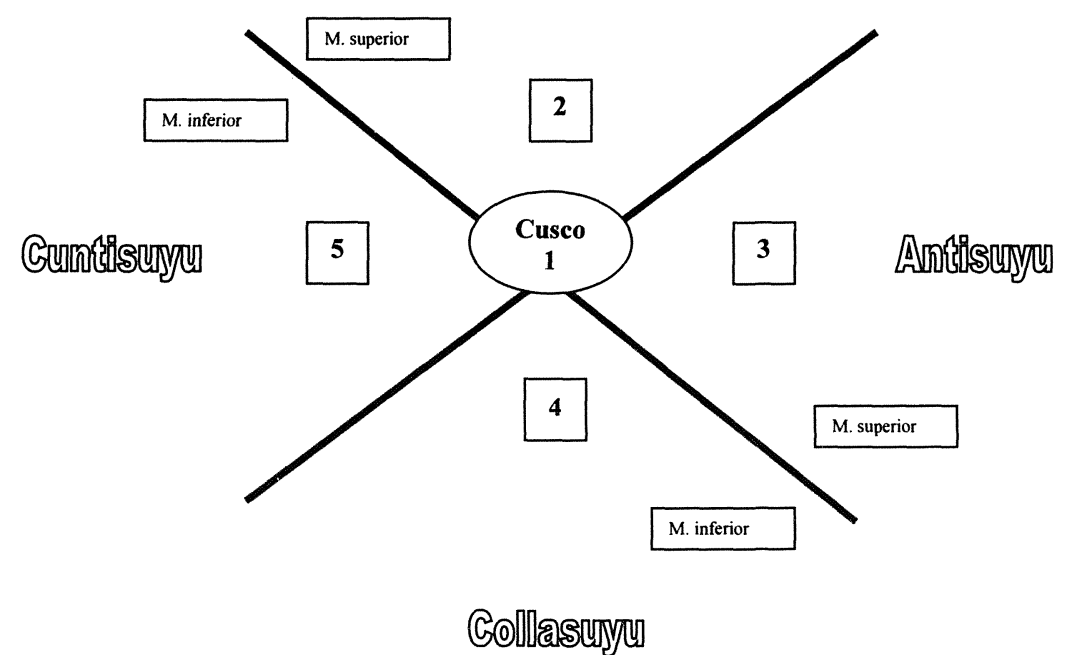

DIAGRAMA 2.-La quinquepartición política de la sociedad andina, según Guaman Poma de Ayala. Fuente: Wachtel 1971a: 801. 
como formando parte de una estructura aún más incluyente, decimal. Como observara Ossio (1973: 181-184) y más recientemente Szemińsky (1982-1984: 105-106), no sólo el pasado prehispánico sino también el presente hispánico aparecía dividido en cinco fases, lo que hacía un total de diez, que el autor indígena enumeraba al final de su texto (Guaman Poma 1980: 911[925]). Estas fases eran las siguientes: 1) "Uari Uira Cocha runa", 2) "Uari runa", 3) "Purun runa", 4) "Auca runa", 5) "Yncap runan", 6) "Pachacuti runa [...], aucanacuscan pacha, cutiscan pacha", 7) "Conquista Cristiano [sic] runa [...], conquistascan pacha", 8) "Cristianopachapi, auca tucuscan rreyninchicmanta quiuicuscan, alsascan pacha [...], auca tucuscan pacha runa", 9) "Allin tactalla cristiano justicia" y 10) "Cristiano cayninchic yallin".

En este esquema, que duplica el anterior de cinco "soles" o "generaciones" (runa), Guaman Poma definía el sexto periodo como el de la guerra de sucesión entre los Incas Guáscar y Atahuallpa que había facilitado la conquista española y la caída del Imperio; nótese que el autor caracterizaba este episodio como pachakuti, a modo de solución de continuidad entre dos mundos y dos tiempos. El séptimo periodo era el de la conquista española [hasta 1537]. El octavo, el de las guerras entre los conquistadores [entre 1537 y 1554]. El noveno, el del virreinato del Perú tras esas guerras, integrado en la monarquía cristiana de Felipe II y después de Felipe III; es el periodo en que vivió el autor. El décimo y último es el futuro que Guaman Poma supuestamente deseaba y en el que creía: el de una cristiandad más justa y universal presidida por el rey de España.

Szemiński ha llamado la atención sobre el posible paralelismo estructural que se daría entre las cinco "generaciones" prehispánicas y los periodos 6 a 10, como si se tratara de un ciclo repetido de cinco fases que empezaba con un estado de desorden y dispersión y culminaba en otro de orden y unificación. La duración precisa en años de las fases no tendría un valor literal sino simbólico: el de dar un sentido temporal, el que fuera, a las unidades de la partición. En el pensamiento indígena transmitido por Guaman Poma, esta estructura periódica pertenecería a un sistema todavía más amplio de ciclos de diversificación y unidad cosmológica, comenzado mucho antes de la existencia del primer ser humano en la Tierra (Szemiński 1982-1984: 120-122).

Ossio y Wachtel observaron que la futura unificación cristiana universal bajo el rey de España imaginada por Guaman Poma seguía el modelo adoptado por el mismo autor para describir la más alta jerarquía del poder en el imperio incaico. La preeminencia del Inca sobre los cuatro gobernadores de los suyu prefiguraba, en la nueva unificación de la fase 10, la del monarca español sobre los reyes de las cuatro partes del mundo, sus subordinados: el rey de "las Indias", el de "Guinea", el de "los cristianos de Roma" y el de 
"los moros de[l] Gran Turco". Pero se trata de una prefiguración invertida, reflejando la subordinación de las Indias y "Guinea" en la realidad colonial respecto de "Roma" y el "Gran Turco". El rey de las Indias había pasado a ocupar la posición y el rango que antes había tenido el gobernador del Collasuyn, la región sur y cuarta en importancia; el de Guinea, la del gobernador del Cuntisuyu, la region oeste y de menor rango de las cinco; el de Roma, la posición del Chinchaysuyu, la región norte y de más alto rango después de Cusco y el Inca; y el de Turquía, la del Antisuyu, la región oriental y la siguiente en importancia tras el Chinchaysuyu (véase el diagrama 3).

Es obvio que las relativas posiciones de los cuatro reyes subordinados no guardaban relación con las ubicaciones geográficas de cada uno de los países respectivos. Pero lo que contaba era el orden jerárquico entre las "cuatro partes del mundo" (los suyu) bajo los Incas, el cual Guaman Poma deseaba que se mantuviera, aunque el mundo se hubiera hecho mucho más grande bajo los españoles. El Cbinchaysuyn y el Antisuyu habían constituido la mitad superior del imperio inca; el Collasuyu y el Cuntisuyu, la mitad inferior. En el régimen virreinal, Las Indias y Guinea habían pasado a ocupar la mitad inferior; pero teniendo Las Indias, a ojos de Guaman Poma, mayor status que Guinea, le debía corresponder la posición superior dentro de la mitad inferior, que era la del Collasuyu o sur. Del mismo modo, teniendo los cristianos y Roma un status más alto que el reino del Gran Turco, su posición había

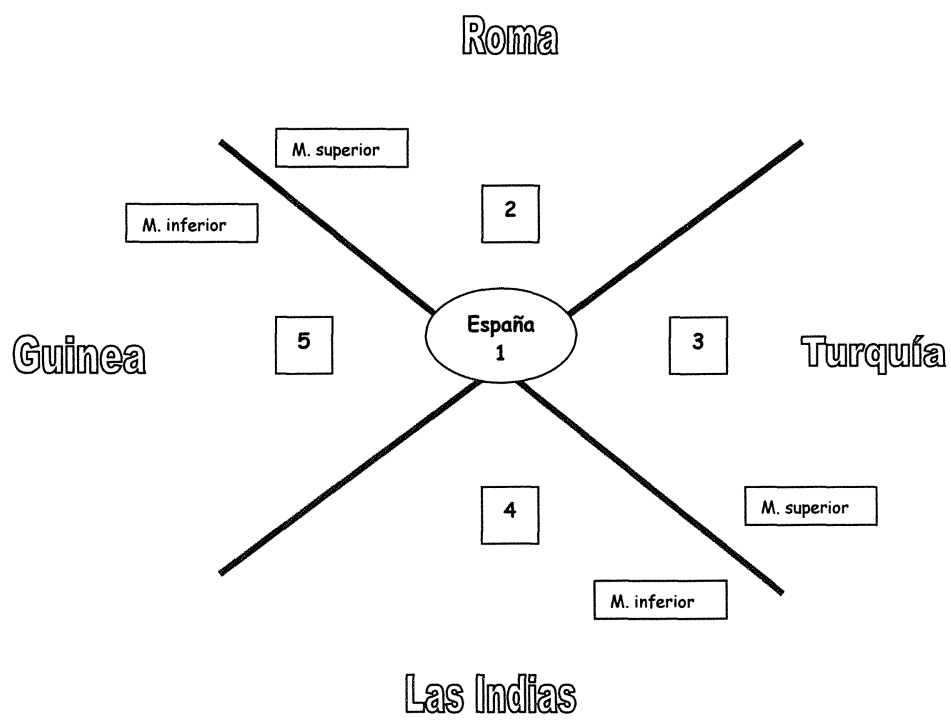

DiAgrama 3.-La quinquepartición política del mundo colonial para Guaman Poma de Ayala. Fuente: Wachtel 1071a: 835. 
de ser la de mayor rango dentro de la mitad superior, que era la del Chinchaysuyu o norte, quedando entonces para el Gran Turco la posición del Antisuyu. Este orden jerárquico cuadripartito, bajo el poder del Rey de España como quinto elemento y centro unificador, es el que se proyectaba en cada ciclo de cinco fases, incluido el inaugurado con el pachakuti de la crisis del imperio inca. Por consiguiente, de nuevo la diacronía —el paso del tiempo y de la historia - se nos ofrece, en una representación indígena como ésta de Guaman Poma, como producto de una sencilla transformación conceptual de una estructura sincrónica y estática (Wachtel 1971a: 832-835; Ossio 1973: 179-181; 1977: 43-45).

Duviols ha puesto después en entredicho este planteamiento argumentando (1980b: 8; 1980-81: 111-112) que la estructura de las cinco edades o "generaciones" en Guaman Poma no habría sido indígena, sino tomada de la tradición judeocristiana llevada a los Andes por los españoles ${ }^{7}$. Su argumento recuerda al de Arnoldsson, en 1956, acerca de la posible influencia del concepto occidental de la Edad de Oro en racionalizaciones históricas americanas como la de Guaman Poma (Arnoldsson 1965: 11-12). Sin embargo, el concepto de la Edad de Oro forma parte de una racionalización primitivista: la que toma el tiempo de los orígenes como modelo o fuente de inspiración para el devenir histórico. La del autor andino no podría caracterizarse bien así: su modelo no es la primera edad sino la unificación del Tawantinsuyu en la quinta, aunque Guaman Poma lamentaba que fueran los Incas quienes la hubieran logrado - a los cuales consideraba usurpadores- y no los nobles antepasados del autor en el Perú central.

Los esquemas de periodización en la tradición cultural europea que Duviols señala como más parecidos al expuesto por Guaman Poma y que éste pudo haber tomado como modelos, son también demasiado distintos como para pensar que ocurriera realmente así. Uno de tales esquemas procede de una exégesis del Pentateuco por San Isidoro de Sevilla, donde se distinguen cuatro edades (las de Adán y Eva, Abraham, Moisés y David) hasta el advenimiento de Jesucristo, que daría paso a la quinta edad y última. Guaman Poma consideró esta misma periodización al tratar de la historia del Viejo Mundo como preámbulo a su disertación sobre el pasado preincaico. Incluso concedió a éste una duración de 5.300 años, lo que no está lejos de los 5.228 años que San Isidoro atribuyera a toda la historia recogida en el Antiguo Testamento.

\footnotetext{
7 Todavía más recientemente, Rostworowski (1988: 60-61) y Julien (2000: 298) han hecho suyo también este parecer, aunque sin detenerse a considerar los méritos de una teoría que busque en la cosmología andina sobre el espacio los fundamentos de esa partición temporal.
} 
En cuanto al segundo esquema, procede de la profecía contenida en el Libro de Daniel, la de que el Reino de Dios sobrevendrá luego de una sucesión de cuatro reinos terrenales: uno de oro, otro de plata, el tercero de bronce y el cuarto de hierro. A diferencia del primitivismo, tanto el esquema de San Isidoro como éste del Libro de Daniel ofrecen una racionalización teleológica -muy propia del concepto de tiempo judeocristiano- que está más próxima a la de las cinco edades de Guaman Poma.

Pero el primer problema que salta a la vista, reconocido por Duviols (198081: 111-112), es que estas cinco edades en el autor andino no incluyen al cristianismo. Aunque Guaman Poma trata ciertamente de él -como novedad que sobreviene con el fin del imperio inca-, incluirlo en su esquema exige contemplar entonces seis edades y no cinco; en realidad, diez, de acuerdo con el razonamiento de Ossio y de Szemińsky. Lo cual nos devuelve a la estructura decimal de la que formaría parte la quinquepartición. Como hemos visto, esta estructura decimal encerraba un concepto periódico de la diacronía, al estar compuesta de dos ciclos de cinco fases cada uno. Era éste un concepto extraño a la teleología judeocristiana y, por ello, es la mejor señal de que el esquema de las cinco edades tiene factura indígena. Es sabido que la quinquepartición y la división decimal como principios estructurales están muy presentes en diversos ámbitos de la organización del imperio inca, tratados por Guaman Poma y otros autores: como en el ámbito demográfico, con la clasificación de la población en diez grupos de edad (Rowe 1958; Zuidema 1964: 46, 215-218); o en el ámbito militar y administrativo, con la división en contingentes de $5,10,50,100,500$ y 1.000 soldados o tributarios (Zuidema ibid:; Wedin 1965; Wachtel 1971b: 127); o, como vamos a ver, en la misma organización de los incas en Cusco. La periodización que Guaman Poma hace para la historia del Antiguo Testamento, desde Adán y Eva hasta Jesucristo, sería un caso más de estructuración indígena, como han apuntado Wachtel (1971a: 828) y Szemińsky (1982-84: 121-122).

\section{LA EDAD DE LOS INCAS}

A la quinta edad o "generación", la de los Incas (Incap runan), Guaman Poma le asignó una duración mucho mayor que la que le atribuyera Montesinos. Pero las cifras que aquél ofrece al respecto son contradictorias entre sí. En una parte de su obra (Guaman Poma 1980: 48-78) dice que la primera edad (Uari Uira Cocha runa) había durado 830 años, la segunda 1.312 y la tercera 1.100; sorprendentemente, para la suma de las tres da la cifra de 3.200 años y no 3.242 , como aritméticamente tendría que ser. De la cuarta edad dice que había durado 2.100 años; por lo que sumando esta cantidad a los 3.200 años que según él había sido la duración total de las 
tres anteriores, el resultado arroja la cifra de los 5.300 que hemos visto antes que ofrece para toda la "historia" preincaica. Y ya que escribe también que el tiempo transcurrido desde la llegada del primer hombre a las Indias hasta la fecha en que él escribía, 1.613, había sido de 6.613 años, si se sustraen de esta cantidad los 5.300 años de la época preincaica y los 81 años pasados desde la llegada de los españoles hasta 1.613, el resultado arroja una duración de 1.232 años para la edad de los Incas. Esta edad habría empezado entonces en el año 300 del nacimiento de Jesucristo.

Sin embargo, en otra parte de su obra (1980: 31) Guaman Poma escribe que Jesucristo había nacido en Belén cuando en el Perú reinaba el segundo Inca,"Cinche Roca"; lo que obliga a retrotraer el comienzo de la edad incaica al menos una generación antes del comienzo de nuestra era. Ahora bien, Guaman Poma describe una sucesión de 13 Incas en total hasta la llegada de los españoles; si el primer Inca reinó una generación por lo menos antes del nacimiento de Jesucristo, aumentando con ello la duración de toda la edad a unos 1.600 años, los trece reyes habrían reinado entonces un promedio de 123 años cada uno, lo que es una cifra sencillamente increíble. Si, por el contrario, la edad hubiera durado 1.232 años, la implicación seguiría siendo inaceptable: un promedio de 94,7 años por reinado ${ }^{8}$.

Sirva este problema de correlación de fechas entre la llamada "Edad de los Incas" y la Era cristiana para significar de nuevo que las cifras ofrecidas por la tradición indígena —en este caso, representada por Guaman Pomano pueden tomarse en el sentido que tenían para los españoles. Al autor andino no le importaban mucho las dataciones absolutas, por corresponder a una historia ascendente e irreversible que no era la suya. Incluso son muy imprecisas, cuando no erróneas o contradictorias, las fechas que ofrece para los acontecimientos posteriores al inicio de la conquista española, para los que se cuenta con medios de corroborarlas; entre tales fechas están hasta las relativas a su propia edad (Porras Barrenechea 1948: 20-26). Ossio ha argumentado por eso que, si Guaman Poma escribió que las cuatro edades preincaicas habían durado 5.300 años, habría querido decir en realidad 5.000 años; esto es, cinco "soles", de acuerdo con la terminología transmitida por Montesinos. La desviación respecto de la cifra original habría obedecido a la influencia cristiana (Ossio 1977: 46-49).

Sin embargo, más coherente aún con la estructura de Montesinos sería otorgarle 5.000 años a la suma de esas cuatro edades más la de los Incas, dando un "sol" y dos pachakuti a cada una. Esta opción interpretativa per-

\footnotetext{
${ }^{8}$ Los incas conocían el año lunar además del solar; pero reducir el uno al otro no arroja un resultado que fuera más de recibo: 1.232 años lunares equivalen a 1.194 solares, dando un promedio de 92 años por reinado.
} 
mitiría resolver, de paso, la incongruencia de Montesinos que hemos visto antes: la que resulta de, por un lado, asignar al periodo incaico una duración de 400 a 500 años, en línea con otros autores, como Polo de Ondegardo (lo que implica un solo pachakuti adicional a los ocho nombrados, que tiene que coincidir necesariamente con la llegada de los españoles en el año 4.500 desde el Diluvio) y, por otro lado, adscribir esta solución de continuidad al reinado del Inca séptimo, en una lista de once (lo que implica dos pachakuti adicionales: el de ese reinado revolucionario y el de la conquista española). Conceder mil años a la sucesión de los Incas —en vez de quinientos- sería una forma de resolver este conflicto, al reunir ambas versiones en un único sistema "histórico": el de una secuencia de diez siglos en que habría habido un pachakuti, el noveno, al cabo de los primeros cinco siglos, y otro más, el décimo, al producirse la invasión de Pizarro y sus hombres cinco siglos después. Este décimo pachakuti habría significado el fin del quinto "sol" desde el Diluvio, el sol de los Incas, así como el principio del sexto, el de los españoles.

La obra de Sarmiento (1988) corrobora que tal teoría histórica sugerida por Guaman Poma estaba, en efecto, en circulación en los siglos XVI y XVII. Sarmiento distribuye en cerca de un milenio los reinados de un total de doce Incas, de la manera siguiente:

\section{Fecha de fallecimiento \\ Años de reinado (Era Cristiana)}

Dinastía Hurin:

$\begin{array}{lrl}\text { 1. Manco Cápac } & 100 & 665 \\ \text { 2. Sinchi Rocca } & 19 & 675 \\ \text { 3. Lloqui Yupanqui } & 111 & 786 \\ \text { 4. Mayta Cápac } & 100 & 896 \\ \text { 5. Cápac Yupanqui } & 89 & 985\end{array}$

Dinastía Hanan:

\begin{tabular}{lrr} 
6. Inca Rocca & 103 & 1088 \\
7. Yáhuar-Huacca & 96 & - \\
8. Inca Viracocha & 101 & - \\
9. Pachacuti Yupanqui & 103 & 1191 \\
10. Túpac Inca Yupanqui & 67 & 1258 \\
11. Huayna Cápac & 60 & 1524 \\
12. Huáscar Inca & 9 & 1533 \\
\multicolumn{1}{c}{ TOTAL } & 949 & 968
\end{tabular}

Sarmiento no incluyó en la lista a Atahuallpa, a quien venciera y capturara Pizarro en noviembre de 1532 de la Era Cristiana. Al contrario que otros autores españoles, como Cieza y Betanzos, Sarmiento lo consideraba un usur- 
pador. Pero aun contando con él, no se alterarían las cifras totales ofrecidas por Sarmiento: sabemos con certeza que Atahuallpa murió en 1533, igual que su hermanastro, "Huáscar Inca", y su reinado, legítimo o no, había coincidido en parte con el de éste al controlar cada uno su porción del Imperio en la guerra civil desatada tras la muerte del padre de ambos, el emperador "Huayna Cápac".

Más significativo, para el asunto que nos ocupa, es el valor que tienen las cifras dadas por Sarmiento. Nótese, en primer lugar, la contradicción entre la suma de los años de los doce reinados (949 años) y la duración total de la sucesión (968 años). Es la discrepancia más llamativa, que puede haber tenido su origen en un movimiento de revitalización indígena conocido como Taki Onqoy ocurrido unos años antes de que Sarmiento escribiera su Historia, hacia 1565, como pensaron Zuidema (1964: 227-235; 1973: 25-27) y Wachtel (1971: 272-273). Sarmiento, afectado por la ideología de este movimiento antiespañol y anticristiano transmitida por alguna de sus fuentes, habría datado la subida al trono del primer Inca, Manco Cápac, en el año 565, para situar en esa fecha el comienzo de un ciclo milenario al que en 1533 le faltaban aún 32 años por cumplirse. Después, Sarmiento habría olvidado corregir la duración de los reinados de los doce Incas para que la cifra total se ajustara a los 968 años establecidos para su historia hasta 1533.

Pero tal falta de ajuste entre los dos cómputos es todavía más reveladora de la teoría cíclica transmitida por Sarmiento. Por ejemplo, del segundo Inca, "Sinchi Rocca", dice el español que reinó durante 19 años; sin embargo, la correlación que establece con fechas de la Era Cristiana indica que este rey ocupó el trono sólo 10 años: entre el 665 y el 675. Para los Incas séptimo y octavo, "Yáhuar-Huacca" y "Viracocha", Sarmiento no da las fechas de sus fallecimientos; pero tampoco éstas se pueden extrapolar, puesto que el año de la muerte del Inca siguiente, el rey Pachacuti, que es 1191, es incongruente con las duraciones de los reinados correspondientes, que suman 300 años entre los tres. Además, el Inca número once, Huayna Cápac, no pudo haber reinado durante 60 años y haber muerto en 1524 si su padre, "Túpac Inca Yupanqui", había fallecido en 1258, como escribe también el autor español.

Obsérvese esta sospechosa duración de los reinados: todos, salvo el del segundo Inca y los dos últimos, son de 100 años u oscilan en torno a esta cifra. Los dos últimos no hay duda de que fueron emperadores históricos en nuestro sentido del término, aunque la duración real de sus reinados sea incierta: fueron conocidos de los primeros españoles, o de los naturales con quienes éstos trataron. En cuanto al segundo Inca, Sinchi Rocca, si bien Sarmiento le otorga a su reinado la creíble cifra de 19 años, también ofrece el intrigante dato de que este rey contaba 108 años de edad cuando sucedió a 
su padre, muriendo a los 127. En coherencia con las edades que da el autor de los demás Incas al acceder al trono, podría pensarse que Sarmiento trastocó las cifras en este caso y quiso en realidad decir que Sinchi Rocca contaba 19 años cuando sucedió a su padre y luego reinó 108 años, falleciendo a los 127. Si así fuera, la duración total para la sucesión de los doce Incas, incluidos los dos históricos, habría sido de 1.048 años. Los históricos habrían reinado entonces durante 48 años y los anteriores, un milenio.

Pero si así no fuera, tendríamos todavía una cifra promedio para los reinados de nueve de los doce reyes que se aproxima a los cien años y que es tan históricamente inaceptable como la sugerida por Guaman Poma para los trece suyos y que, como en este caso, hace pensar mejor en una estructura decimal encubierta. Zuidema, advirtiendo algunas de las anomalias y la extraña naturaleza de las cifras dadas por Sarmiento, propuso esta explicación (Zuidema 1964: 227-235; 1973: 20-27). Rowe había considerado tales cifras del todo inutilizables ("wild and impossible", escribió), aferrándose por el contrario a las aparentemente verosímiles - pero inexplicadas- de otro autor español, Miguel Cabello Balboa, para los cinco últimos Incas de la lista; de acuerdo con ellas, la llegada al poder del noveno soberano, el rey Pachacuti, se habría producido en el año 1438 de la Era Cristiana (Rowe 1945: 277). El investigador norteamericano no se detuvo a contemplar entonces la posibilidad de que Sarmiento, al igual que Guaman Poma, hubiera transmitido una tradición "histórica" nativa que, en su versión más original, adscribía un milenio o "sol" a 10 Incas, dando a cada uno un reinado de 100 años. A estos reyes de la estructura se les habrían añadido los Incas históricos, los últimos de la lista.

No se olvide, a pesar de ello, que una tradición así es contradictoria con la transmitida por Montesinos, así como por Polo de Ondegardo y Vázquez de Espinosa, quienes daban a la sucesión de los Incas entre 400 y 500 años. En la versión de Montesinos, como se recordará, esta sucesión había comenzado en el año 4.000 desde el Diluvio Universal.

\section{LOS DESCENDIENTES DE LOS INCAS}

Para explicar y resolver esta contradicción es necesario volver a la organización de Cusco y el Tawantinsuyu. Ya hemos visto que el transcurrir del tiempo y de la historia podía ser racionalizado por los antiguos peruanos como si se tratara de su espacio natural y social; de modo que una mayor información sobre este espacio entre los incas como elite de poder en la capital del país permitiría entender mejor aún la idea que tenían del tiempo y de la historia.

Cada uno de los doce soberanos en la lista de Sarmiento, excepto los 
dos últimos, había dejado descendientes reconocidos en Cusco. Estas personas eran identificadas socialmente, y entre sí, por su pertenencia a uno u otro de los linajes que entroncaban con cada uno de esos diez Incas. Cuando se produjo la invasión española, el universo social integrado por esos diez linajes, constituidos como otras tantas corporaciones, formaba la elite del poder imperial en la capital. Aparte de tener un nombre propio, distinto del nombre del Inca del que presuntamente descendían sus miembros - y al que rendían culto-, cada corporación disponía de tierras, palacios y servidores. En ocasiones señaladas a lo largo del año, las efigies o cuerpos embalsamados de tales reyes o emperadores, así como los. de las reinas correspondientes, eran sacados a la plaza de la ciudad como parte fundamental de complejas ceremonias (v. g., Molina de Cusco 1989: 73-96).

El Inca número once mencionado por Sarmiento, Huayna Cápac, había dejado también descendientes socialmente reconocidos, pero en la localidad de Tumibamba, en el actual Ecuador, donde este soberano había tenido su corte en los últimos años de su vida ${ }^{9}$. El Inca número doce, Huáscar, el último legítimo según Sarmiento, apenas tuvo descendientes que sobrevivieran a la guerra contra su hermanastro, Atahuallpa ${ }^{10}$; en todo caso, no parece que estas personas llegaran nunca a constituir una corporación aparte, pues no les distinguía un nombre propio. En cuanto a Atahuallpa, aunque no contaba para Sarmiento, sus descendientes estaban relacionados con Quito y la frontera norte del Imperio, su base de poder en la guerra contra Huáscar, y no con Cusco. Así pues, este soberano, como sus dos antecesores - Huayna Cápac y Huáscar-, representa una excepción que viene a reforzar el sentido de la que he señalado antes, a propósito de la duración de los reinados: los tres personajes, además de no dejar en la capital descendientes socialmente constituidos como sus diez antecesores, fueron Incas durante un número real de años; esto es, fueron emperadores históricos en nuestro sentido de la expresión. Parafraseando a Zuidema (1973: 23), en la tradición transmitida por Sarmiento la "Historia", en el sentido inca del término,

\footnotetext{
9 María Rostworowski ha argumentado (1983: 141) que este linaje se llamaría así no por la Tumibamba de Ecuador, sino por otra Tumibamba que habría estado en el valle de Xaquixaguana, al noroeste de Cusco, que daría después su nombre a aquélla. Su razonamiento puede invertirse sin dificultad; en cualquier caso, los dos lugares estaban fuera de la capital. La misma investigadora también ha creído ver más de diez linajes reales en Cusco (ibid.: 141-145); sin embargo, los nombres adicionales que ha contado o bien son duplicados o errores de transcripción de los más conocidos (v. g., "Cusco" por "Sucsu"), o bien corresponden a linajes u otros grupos que no estaban entre los reales.

${ }^{10}$ Uno solo, un varón, aparece consignado por Sarmiento como todavía vivo en 1572 (Sarmiento 1988: 175).
} 
habría terminado con la muerte del soberano número diez, Túpac Inca Yupanqui.

Para el investigador holandés, esa tradición de 10 Incas sucediéndose a lo largo de 1000 años, reinando cada uno 100, no podría entenderse sino como una representación, en clave temporal, de la organización social de Cusco, y en concreto de la estructura de los diez linajes reales. Según varios autores, en efecto, como Bartolomé de Las Casas (1892: 146-150), Pedro Gutiérrez de Santa Clara (1963-64: CLXVI, 214) y Martín de Murúa (1987: 501), estos linajes no habían surgido a la muerte de cada soberano, como interpretara Sarmiento y otros españoles, sino que fueron todos constituidos a un tiempo por un gran rey legislador. En la versión de Las Casas, la más completa de esta tradición (aunque no considerada por Zuidema), este rey legislador había sido el Inca número nueve en su lista, el ya conocido "Inga Pachacútic"; nombre que, como hemos visto, cabe entender como una personificación del noveno pachakuti en el cómputo milenario de Montesinos y de Valera. En la versión de Gutiérrez de Santa Clara, el legislador había sido "Topa Inga Yupangue", es decir, el mismo que aparece en último lugar en la estructura decimal transmitida por Sarmiento y que es identificable por sus hechos memorables como "Pachacuti Inca" en aquellas listas en las que éste no aparece, como por ejemplo en la de Montesinos. En la versión de Murúa, el legislador había sido Manco Cápac, el legendario fundador de Cusco y primer rey de los incas en las listas que hemos visto hasta ahora. Es razonable por ello pensar que puede tratarse en todos los casos del mismo personaje o agente mítico: distintos nombres para otras tantas personificaciones del noveno pachakuti, señalando un cambio de época para el año 4.500 desde el Diluvio.

Las Casas sugiere, además, que los linajes eran matrilineales; lo que es otro dato que pone en entredicho la idea de una sucesión dinástica al estilo europeo, patrilineal. Según el célebre dominico, la descendencia en cada linaje seguía una línea "transversal" (como entre tío materno y sobrino) y no recta, de padres a hijos (Las Casas 1892: 147).

Igualmente significativo para el problema tratado aquí es que las diez corporaciones estaban agrupadas, territorial y socialmente, en dos series de cinco, que Las Casas llama "barrios o partes o bandos". El primero se llamaba "Hanancuzquo, que quiere decir "la parte o barrio o bando de arriba del Cuzco'. El segundo se llamaba "Rurincuzquo, que significa 'la parte o barrio de abajo del Cuzco"' (Las Casas ibid.: 146). Obsérvese que estos dos nombres son casi idénticos a los de las dos dinastías incas de la tradición historiográfica anterior a Imbelloni: "Hurin-Cusco" y "Hanan-Cusco". La diferencia puede deberse a un error de lectura o de transcripción en la edición del texto de Las Casas. Hurin (y no rurin) significa en quechua "abajo" o 
"inferior"; hanan quiere decir "arriba" o "superior". Este contraste, y al tiempo complementariedad, tenía un fundamento cosmológico. El término hanan se asociaba con lo masculino, con el sol y la luz del día, y con el oro; burin era lo femenino, la luna, la noche y la plata (Garcilaso 1991: 188-192).

Si los diez linajes reales fueron creados todos a la vez, también lo habrían sido los reyes de quienes supuestamente descendían sus miembros. Sus nombres y sus hechos, por consiguiente, no deberían ser entendidos como elementos de una o varias narraciones históricas, en nuestro sentido del término, sino de nuevo como componentes de una estructura sincrónica extraña a nosotros. En otras palabras, las dos dinastías incas no habrían sido propiamente tales, sucesivas, sino otra representación en clave temporal de aspectos de la realidad social en Cusco en los años más cercanos a la invasión española; en este caso, una representación de un dualismo presente en los diez linajes reales. Este dualismo estaba asimismo presente en el concepto del Imperio: la mitad "superior" del mismo, integrada por el Chinchaysuyu y el Antisuyu, constituía el elemento hanan; la mitad "inferior", el Collasuyu más el Cuntisuyu, el componente burin. En coherencia con este principio dual —en el espacio y en la sociedad a la vez-, que Imbelloni no advirtió, es razonable pensar, con Zuidema (1964: 126-128; 1973: 8-11) y con Duviols (1980a), que la forma de gobierno de los incas, al menos en esos mismos años, habría sido una diarquía y no una monarquía: dos Incas y no uno sólo habrían gobernado al mismo tiempo en Cusco y en el Tawantinsuyu, un Inca banan y un Inca burin. Su status y su poder, sin embargo, no habría sido el mismo; el primero habría tenido siempre la preeminencia sobre el segundo y es el que españoles como Sarmiento, así como la historiografía contemporánea, identificarían etnocéntricamente como rey o emperador ${ }^{11}$.

\section{LA DIARQUÍA INCAICA}

La diarquía como forma de gobierno no era ajena en absoluto a la tradición política andina, pues ha sido identificada en la organización de los pueblos o etnias no incas que formaron parte del imperio incaico (Murra 1975b, 1975c). Todavía perduraba en la época virreinal y, en algunas zonas, en el presente republicano. Juan de Matienzo, oidor en la Audiencia de La Plata (actual Sucre), la describió muy bien en un conocido texto de 1567, al tratar de los cacicazgos de lo que es hoy la alta Bolivia:

\footnotetext{
${ }^{11} \mathrm{Al}$ malentendido también pudieron haber contribuido informantes incas de los linajes hanan, como ha apuntado Duviols (1980a: 189-190). Tales informantes habrían ocultado o disimulado toda referencia a la diarquía como medio de intentar salvaguardar su status en el régimen virreinal y ante autoridades que no podían entender bien otra forma de gobierno legítima que no fuera la monárquica.
} 
Los caciques, curacas e principales son los príncipes naturales de los indios, y los que los gobiernan y mandan con muy gran concierto, aunque con muy gran tiranía [...]. En cada repartimiento o provincia hay dos parcialidades: una que se dice banansaya, y otra de burinsaya. Cada parcialidad tiene un cacique principal que manda a los prencipales [sic] e indios de su parcialidad, y no se entremete a mandar a los de la otra, excepto que el curaca de la parcialidad de banansaya es el principal de toda la provincia, y a quien el otro curaca de burinsaya obedece en las cosas que dice él [...]. Éste de hanansaya es el principal de todos y tiene [...] señorío sobre los de burinsaya. Llama y hace juntas y gobierna en general, aunque no manda en particular. Cobra la tasa y págala [a las autoridades españolas], porque aunque no la cobra de los de burinsaya en particular, cóbrala del curaca o cacique principal de los de burinsaya, el cual ha cobrado de sus ayllos (Matienzo 1967: 20-21).

Los "ayllos" o "ayllus" eran los grupos de parentesco, poseedores colectivos de tierras y otros bienes, en que se dividía cada una de las dos "parcialidades" o mitades del "repartimiento" o "provincia". En el mismo año 1567, en la provincia de Chucuito, en la cuenca del lago Titicaca, el cacique de la parcialidad de hanansaya - ex officio el "cacique principal" de la provincia- lo era por encabezar en esa parcialidad el "ayllo" de mayor rango; paralelamente, el cacique de la parcialidad de burinsaya era asimismo el jefe del "ayllo" de mayor rango en esa parcialidad (Díez de San Miguel 1964: $5 \mathrm{v}-17 \mathrm{r}$ ). Quien encabezara la parcialidad superior en un determinado nivel organizativo, encabezaba asimismo la superior en el siguiente nivel más incluyente del cacicazgo, y así sucesivamente hasta culminar en la totalidad de él. Esta curiosa forma de organización y distribución del poder se ha encontrado en diversas zonas de la América andina en el siglo XVI, incluida la costa septentrional del Perú (Netherly 1984: 228-233). Estructuralmente, y a su escala, los "ayllos" en estos cacicazgos ocupaban una posición que era equivalente a la de los linajes reales en el Cusco imperial, agrupados asimismo en dos "parcialidades": hanan y burin. Indirectamente, y sin darse cuenta, varios autores españoles de los siglos XVI y XVII corroboran la existencia de un régimen así entre los incas - $\mathrm{y}$, por tanto, a escala de todo el Tawantinsuyr - cuando hacen referencia al cargo de "lugarteniente" o "segunda persona" del Inca (v. g., Betanzos 1987: 111, 131; Guaman Poma de Ayala 1980: 16[16], 184[186], 341[343]; Garcilaso de la Vega 1991: 353, 385, 398). Tal "lugarteniente" o "segunda persona" debía de ser el Inca de la "parcialidad" burin ${ }^{12}$.

\footnotetext{
${ }^{12}$ Apoya esta interpretación lo descubierto por Netherly en la organización política y económica de la costa norte del Perú en el siglo xvi. Esta investigadora encontró en las fuentes correspondientes - documentos generados por la administración española del territorio- que la expresión "segunda persona" del "cacique principal" hacía referencia al jefe de la parcialidad inferior en el cacicazgo (Netherly 1984: 231-232).
} 
Una corroboración más clara, señalada asimismo por Zuidema y después por Duviols, se puede encontrar en la obra del jurista y corregidor en Cusco Polo de Ondegardo (1982) y en la del misionero jesuita José de Acosta (1987). Cieza de León también había sido informado de esta extraña forma de gobierno; sin embargo, le pareció increỉble, según él mismo reconoce, y por ello no la describe en su obra (1985: 113). Es otra muestra de su reconocida honradez profesional, pero igualmente de que hizo algo más que poner por escrito lo que le decían sus informantes. Polo de Ondegardo escribió que, entre los incas,

Cada ayllo o linaje tenían [sic] sus ídolos o estatuas de sus Incas. Las cuales llevaban a la guerra y sacaban en procesión para alcanzar agua y buenos temporales, y les hacían diversas fiestas y sacrificios [...]. Fue la primera [estatua la de] Inca Roca, cabeza de la principal parcialidad de los incas de Hanan Cuzco. Y por su orden le sucedieron Yahuarhuaqui, Viracocha Inca, Pachacuti Inca, Topa Inca Yupanqui, Huayna Capac, Huascar Inca. De la parcialidad de Urin Cuzco se cuenta el primero, Cinchi Roca; y tras él, Capac Yupanqui, Lluqui Yupanqui, Mayto [sic] Capac, Tarco Huaman. El principio [...] dicen haber sido Manco Capac, que después del Diluvio dicen baber sido Progenitor y Padre de las gentes (Polo de Ondegardo 1982: 461). (Acotaciones y cursiva mías.)

El jesuita Acosta, quien bebió en Polo de Ondegardo, pero debió de basarse también en al menos otro testimonio, escribió algo semejante:

El primer hombre que nombran los indios por principio de los ingas, fue Mangocapa [...]. Éste dicen que dio principio a dos linajes principales de ingas: unos se llamaron Hanancuzco y otros Urincuzco, y del primer linaje vinieron los Señores [Incas] que conquistaron y gobernaron la tierra. El primero que hacen cabeza de linaje de estos Señores que digo, se llamó Ingaroca [...]. A Ingaroca sucedió Yaguarguaque [...]. A éste sucedió [...] Viracocha Inga [...]. A éste sucedió Pachacuti Inga Yupangui [...]. A éste sucedió [su hijo] Topa Inga Yupangui, y a éste, otro hijo suyo llamado del mismo nombre, que fundó la familia que se llamó Capac Ayllo [...]. Al dicho Señor sucedió Guaynacapa [...]. A Guaynacapa, sucedió en el Cuzco un hijo suyo que se llamó Tito Cussi Gualpa, y después se llamó Guascar Inga [...]. En la otra parcialidad del Urincuzco, que como arriba se dijo se derivó también del primer Mangocapa, se cuentan ocho sucesores [...]. A Mangocapa sucedió Cinchiroca; a éste, Capac Yupanqui; a éste, Lluqui Yupangui; a éste, Mayta Capa; a éste, Tarco Guaman; a éste, un hijo suyo, no le nombran, y a éste, D. Juan Tambo Maytapanaca (Acosta 1987: 420-426). (Acotaciones y cursiva mías.)

Polo de Ondegardo había nombrado a cinco soberanos de "Hurin Cuzco" y a siete de "Hanan Cuzco", aunque los dos últimos de entre éstos son los que pueden ser considerados Incas históricos en nuestro sentido de la palabra. Su lista, por consiguiente, lleva también incorporada la estructura decimal de reyes que ya hemos visto implícita en la obra de Sarmiento y en la de Guaman Poma. Y como en estas obras, así como en la de Montesinos, el 
esquema presenta el tema del gran Inca fundador (Manco Cápac) separado del concepto de "Rey Pachacuti".

Acosta, por su parte, enumeró a siete Incas de "Hurin Cuzco" (aunque diciendo que eran ocho) y a ocho de "Hanan Cuzco" (aunque distribuidos en siete generaciones). Pero también estos reyes ponen de manifiesto el esquema decimal, aunque Acosta se desvía un poco más de él. Por un lado, los Incas uno a cinco de "Hurin Cuzco" son los mismos que en la lista de Polo de Ondegardo; Acosta añade a ella dos más, pero de uno no facilita el nombre y del otro dice que se llamaba "D. Juan Tambo Maytapanaca", un nombre cristiano que no puede ser anterior a la llegada de los españoles. En consecuencia, estos dos personajes sobrantes de la estructura habrían sido asimismo personajes históricos en nuestro sentido de la expresión ${ }^{13}$.

En cuanto a los soberanos de "Hanan Cuzco", serían los mismos que los de la lista de Polo de Ondegardo si no fuera por la duplicación del nombre "Topa Inga Yupangui" para dos hijos del rey "Pachacuti Inga Yupangui". Esta duplicación puede haber nacido de la disociación de uno de los emperadores llamados así con el "Pachacuti Inga Yupangui" (en otras versiones, como la de Montesinos, uno de los "Topa Yupangui" es el "Inca Pachacuti"), dando como resultado cuatro sucesores del Inca "Yaguarguaque" (el "YáhuarHuacca" de Sarmiento) en vez de tres como ocurre en la mayoría de las listas.

Pero más significativo que esta pequeña desviación del esquema sucesorio es que, como observara Zuidema, las listas de Polo de Ondegardo y de Acosta son, en conjunto, la evidencia más clara de que el dualismo presente en la organización social de Cusco afectaba también al orden político. Con independencia del número y los nombres de los Incas mencionados, nótese

${ }^{13}$ En realidad sólo uno, el último, si aceptamos que "Tarco Huaman" y "Cápac Yupanquin (el mencionado en segundo lugar) habían sido hermanos, como indica Sarmiento (1988: 69). El hijo no nombrado de "Tarco Huaman" representaría entonces a la quinta generación de Incas en la parcialidad burin, que es el límite impuesto por la estructura decimal en esa parcialidad. El último burin mencionado, el séptimo, queda fuera de la estructura y lleva un nombre cristiano. En 1572, un hombre llamado "don Juan Tampu Usca Mayta de sesenta años", del linaje real (o "panaca") burin de Mayta Cápac, figura entre los incas de Cusco a quienes se convocó para ratificar la Historia de Sarmiento (Sarmiento 1988: 69, 174). Siguiendo a Zuidema (1964: 126-128; 1973: 9-11), es probable que se trate de la misma persona identificada por Acosta como último Inca burin. Acosta y Sarmiento coincidieron en Perú unos mismos años, en la década de 1570. El personaje nombrado por Acosta, si fuera realmente el mencionado por Sarmiento, pudo no haber sido realmente el último Inca burin en esos años, pero al menos tal título existía aun después de la llegada del cristianismo -no era, por consiguiente, sólo un asunto del pasado incaico- y "don Juan Tampu Usca Mayta" era ciertamente un inca burin en 1572. 
que tanto Polo de Ondegardo como Acosta nombran a los hanan primero, y a los burin después. Es una singularidad que refleja el diferente status de las dos "parcialidades" incas en la organización de la ciudad y, al tiempo, contradice diametralmente el sentido de las listas de Sarmiento y Guaman Poma, así como de Cieza de León, Betanzos y los demás autores que interpretaron o dieron a entender que una primera dinastía burin había precedido a una segunda, hanan. En Polo de Ondegardo y Acosta, la diarquía es proyectada hacia el pasado como una estructura de dos dinastías paralelas, en la que la dinastía hanan tiene la preeminencia y hasta el sentido de totalidad, y a la que se hace cargo de toda la política exterior. de Cusco desde el principio. Como razonara Zuidema, la prueba más elocuente de que las dos dinastías eran concebidas como paralelas es que el último Inca burin en la lista de Acosta lleva un nombre cristiano, lo que sería imposible si los soberanos burin hubieran reinado en una época anterior a la de los banan.

A pesar de ello, investigadores contemporáneos reconocidos internacionalmente, como Schaedel (1978), Conrad y Demarest (1984), Patterson (1991) y D'Altroy (2002), apenas han tomado en cuenta este planteamiento, menos aún sus implicaciones. Por el contrario, otros autores recientes, como Rostworowski (1983: 130-179), Pärssinen (1992: 171-235), Hiltunen (1999: 216-221, 236) y, sobre todo, Rowe (1993-1994) y Julien (2000: 16, 55, 86$87,309)$, sí que lo han hecho, aunque para rechazar que la forma de gobierno inca fuera dual e insistir en una lectura historicista de la documentación.

Rostworowski admitió el dualismo como principio clasificador y organizativo; pero, paradójicamente, no la diarquía en el régimen político. Planteó que las fuentes no explican cómo funcionaría un régimen así en la práctica; v.g., cómo se producirían las sucesiones a los dos cargos (1983: 130-131, 174). Pero esta laguna es lógica si se tiene en cuenta que los autores de las fuentes, incluidos Polo de Ondegardo y Acosta, no podían concebir esta forma de gobierno, aunque se hicieran eco de la información que revela su existencia. Más paradójico aún es que la misma investigadora propusiera como alternativa una tetrarquía asimétrica, porque este régimen sería coherente con la división del Imperio en cuatro suyu. En esta tetrarquía, el jefe de mayor rango entre los cuatro jefes de suyn, el del Chinchaysuyu, habría sido el Inca por antonomasia (ibid.: 176-178). Sin embargo, las fuentes tampoco explican cómo funcionaría este sistema en la práctica; por lo que, si se acepta por razones estructurales una tetrarquía, por lo mismo habría que aceptar una diarquía en la que aquélla estaría integrada, como lo estaba la cuadripartición en el principio dual.

La alternativa de Pärssinen (1992: 171-235) es parecida a la de Rostworowski: una monarquía en el marco de una tricefalia. Para este investigador finlandés, el Inca propiamente dicho habría sido el de mayor rango entre tres 
gobernantes que habrían presidido a un tiempo el Tawantinsuyu. En apoyo de esta propuesta ha esgrimido principalmente un criterio ordenador de las instituciones y la cosmología indígenas, adicional a los que hemos visto hasta aquí: la tripartición. Expresiones de este criterio habrían sido la división del espacio social en las categorías "izquierda", "centro" y "derecha" en algunos lugares y la tríada "Sol", "Luna" y "Venus" entre los objetos del culto imperial inca. En la estructura sociopolítica de Cusco, Pärssinen ha creído ver el mismo principio ordenador en los términos "collana", "payan" y "cayao", que hacían referencia a otros tantos rangos en cada uno de los linajes reales. Los linajes estaban jerarquizados y, dentro del linaje principal, los tres personajes de mayor autoridad en él, y por ello en todo el Imperio, habrían sido los primeros en cada uno de esos tres rangos, siendo el de "collana" el más alto y, por ello, el del Inca propiamente dicho; tras él habría existido un Inca "payan" y, en tercer lugar, un Inca "cayao" (Pärssinen 1992: 211-227).

La idea de que los términos "collana", "payan" y "cayao" expresan una tripartición jerárquica en la estructura social y política de Cusco procede de Zuidema (1964: 39-42) y después de Rowe (1985a, 1985b), quienes no por ello pensaron que la cúspide del poder incaico había sido tripartita. El principio de la tripartición, aunque indiscutible en determinados ámbitos, no es relevante para el tema que nos ocupa. Además, los términos "collana", "payan" y "cayao" no expresan propiamente una tripartición, pues formaban parte de una clasificación más incluyente, cuadripartita ("collana", "payan", "cayao" y "caru"), para indicar distintos grados de distancia generacional a un antepasado común en un linaje (Pérez Bocanegra 1631: 613).

La aportación del también finlandés Hiltunen (1999), en la parte que difiere de la de Rowe y Julien —que trataré a continuación-, tampoco es muy convincente, ya que parte de una consideración transcultural (o "etic"), que no específicamente andina, del imperio inca y otras formaciones políticas del Perú prehispánico. Visto con esta perspectiva comparativa, el principio dual resulta ser un fenómeno extraño en una civilización antigua, siendo más propio de sociedades pre-estatales, o al menos pre-imperiales. Para Hiltunen, el inca era, ante todo, un imperio; desde su formación estuvo sometido a frecuentes crisis internas que exigían un poder central fuerte y unificado, como en otros imperios históricos. Estas mismas circunstancias militarían, en el plano psicológico, contra una hipotética diarquía: un emperador, sea por ambición o por desconfianza, no puede tolerar durante mucho tiempo el compartir el poder con otra persona, salvo tal vez que ésta sea su esposa. Además, una dualidad en la forma de gobierno sería incongruente con una imagen del Inca como "Padre", "Dios" y "Señor" de "Las Cuatro Partes del Mundo" que se lee en las fuentes (1999: 218-221, 236).

Sin embargo, ya hemos visto que los dos cargos en la diarquía incaica no 
habrían tenido el mismo rango y poder; habría sido el soberano hanan el que tendría la preeminencia entre los dos, y el que aparecería identificado con lo externo a Cusco y con la totalidad del imperio. Un régimen así no es incompatible por principio con una potestad centralizada y autoritaria. Y aunque era ciertamente un imperio lo que encontraron los españoles en la conquista del Perú, en su organización y funcionamiento regían criterios y modos propios de las sociedades tribales; v. g., la importancia en él de las relaciones de parentesco.

Hiltunen admite que la lectura literal de la sucesión de los Incas, del mismo modo que la de los soberanos pre-incaicos en la larga lista de Montesinos, no puede sostenerse y se hace necesaria una exégesis. Pero la propuesta por él descuida lo que ya sabemos de la cosmología andina; por el contrario, tiene sus principales fundamentos interpretativos en otras formaciones históricas y culturales. El investigador finlandés piensa así que las narraciones sucesorias del Perú prehispánico habrían sufrido, aparte las distorsiones de los españoles, los típicos efectos de la propaganda política identificados en esas otras sociedades; como es el caso, por ejemplo, de las interpolaciones hechas a los poemas épicos de la India antigua, el Rigveda y el Mahabharata, o las operaciones de damnatio memoriae en los anales del Egipto faraónico y en la China del siglo III a.C. (Hiltunen 1999: 118-144).

Esta observación sería aceptable si no fuera aducida en apoyo de la existencia de un concepto lineal del tiempo y de la historia entre las elites andinas, por contraposición al concepto cíclico que habría tenido el pueblo llano (ibid.: 145). Partiendo de este supuesto, Hiltunen ha intentado reconstruir las series dinásticas originales - libres de las presuntas manipulaciones propagandísticas posteriores - reduciendo e interpretando las listas de reyes con procedimientos aplicados a esos otros casos históricos y buscando una correspondencia con la sucesión arqueológica de las culturas preincas desde el año 225 d.C., aproximadamente; esto es, al modo de Riva-Agüero, Means $\mathrm{y}$ otros autores que en las primeras décadas del siglo $\mathrm{XX}$ vieron en la obra de Montesinos un eco de la historia del Perú antiguo, tal como ellos la concebían. Complementariamente, Hiltunen ha buscado la correspondencia con ciertos acontecimientos astronómicos para el mismo periodo de tiempo (v. g., eclipses de sol) y con la lingüística histórica y política del quechua y otras lenguas de la región andina central antes de la conquista española: un terreno éste harto resbaladizo (ibid:: 296-352).

Su empeño es ambicioso y admirable, pero sus bases de sustentación son endebles. A diferencia del Egipto farónico, por ejemplo, se sigue sin contar para el Perú prehispánico con una pluralidad de escritos independientes y contemporáneos con que comprobar la presunta historicidad de una fuente, en nuestro caso la crónica de Montesinos. Desde el punto de vista 
epistemológico, el proyecto de Hiltunen nos devuelve a la situación anterior a Imbelloni. No cabe dudar del recurso de los incas a la propaganda; sin embargo, este hecho, por sí solo, no exige aceptar la existencia de un concepto lineal del tiempo y de la historia, al menos para las narraciones sucesorias. Por el contrario, como hemos visto, textos como los de Montesinos, Valera, Salinas y Córdoba, Guaman Poma y Sarmiento llevan implícito un concepto cíclico de tales sucesiones, identificable si uno analiza estas obras teniendo en cuenta lo que los mismos autores también sugieren de las ideas nativas sobre el espacio y el mundo. Y este concepto cíclico, con independencia de su divulgación entre el pueblo llano, sería el de unas elites políticas, religiosas o intelectuales; pues de ellas debieron de provenir, en último término, las fuentes originales de esos textos. Hiltunen no se ha detenido suficientemente en su contenido antes de proceder a una comparación del Perú antiguo con otros casos históricos.

La posición de Rowe (1993-1994) y de Julien (2000) contra una posible diarquía entre los incas, y en defensa de la teoría monarquista, es la más cuidadosa y meditada; no obstante, se ha circunscrito a un análisis de los ya citados testimonios de Polo de Ondegardo y de Acosta, como si fuera ésta la única evidencia digna de ser tomada en consideración. Tanto Rowe como Julien han argumentado que esta evidencia es más aparente que real. Según ellos, el de Polo de Ondegardo sería realmente el único texto a tener en cuenta, ya que el testimonio de Acosta no sería independiente de él; pero incluso ese texto sería dudoso: pues no es el original del autor (un tratado de religión indígena, de hacia 1560, hoy perdido) sino un resumen del mismo - hecho probablemente por Acosta - para incluirlo, en 1585 (ya fallecido Polo), entre los documentos publicados del III Concilio de la Iglesia del Virreinato. Poco después, en 1561, Polo redactaría un informe sobre la perpetuidad de las encomiendas en el Perú ${ }^{14}$ en el que daría a entender que el régimen de los incas había sido monárquico; en el escribió, por ejemplo, frases como "cuando hazían inga que era su Rey" o "los tributos que éstos daban al señor soberano, que era el inga" (en Rowe 1993-94: 105). Más tarde, en 1572, tres años antes de su muerte, Polo sería convocado ante el virrey Francisco de Toledo para que respaldara el resultado de una investigación ordenada por éste sobre la historia de los Incas, que entre cosas presentaba su forma de gobierno como una monarquía. Polo otorgó ese respaldo, a pesar de que lo averiguado por el virrey Toledo contradecía lo aparentemente escrito por él hacia 1560; lo que indicaría que Acosta malinterpretó el contenido de ese tratado al intentar resumirlo.

\footnotetext{
${ }^{14}$ La encomienda era el título que daba derecho a los conquistadores o sus herederos a exigir trabajo, productos o dinero a la población indígena, a cambio de fomentar su evangelización y defender con las armas el territorio conquistado.
} 
Rowe y Julien también han señalado que hay Incas nombrados en ese resumen y en el texto de Acosta que no figuran en las demás listas de reyes: una singularidad que para ambos autores hace sospechosa la información que tales textos transmiten. Se trata del extra "Topa Inga Yupangui", así como de "Tarco Huaman" y del ya mencionado "D. Juan Tambo Maytapanaca". La anomalía del extra "Topa Inga Yupangui" la ha explicado Rowe argumentando (1993-1994: 103) que Acosta pudo haber llamado por error con ese nombre a un personaje de nombre parecido en otras fuentes: un "Auqui Topa Inga" que fue hijo del emperador "Topa Inga Yupangui", el soberano número diez en la lista de Sarmiento. Según las mismas fuentes, este "Auqui Topa Inga" ("el infante Topa Inga") nunca llegó a reinar. Con respecto a "Tarco Huaman", se habría incurrido en la misma clase de error: tampoco llegó éste a ser nunca Inca. Quien sucedió a "Mayta Cápac" como soberano número cinco fue su otro hijo "Cápac Yupanqui", sin embargo nombrado en segundo lugar por el autor del resumen y por Acosta. Por consiguiente, tanto Acosta como este autor habrían estado mal informados sobre tales personajes (Rowe, ibid.: 104; Julien 2000: 87, 309).

El caso de "D. Juan Tambo Maytapanaca" habría obedecido a un tipo de error distinto. Rowe pensó (ibid.), y con él Julien (ibid.: 309), que Polo -0 tal vez Acosta- pudo haber mezclado datos de dos fuentes difererentes: de un lado, la tradición sucesoria de los Incas ya conocida de otros españoles; de otro, los autos de un litigio sobre tierras ante Polo como corregidor de Cusco hacia 1560. En este pleito, una de las partes enfrentadas incluía como jefe al "Juan Tampu Usca Mayta" mencionado en 1572 por Sarmiento como miembro del linaje real de Maytạ Cápac. Ya que en esta fuente se menciona también a "Tarco Huaman", la referencia a este personaje pudo haber contribuido asimismo a la confusión de Acosta sobre él. Rowe consultó documentos acerca de este litigio en el Archivo Histórico de Cusco. El citado "Juan Tampu" —seguramente el "Juan Tambo" mencionado por Acosta— alegaba que las tierras en cuestión habían pertenecido a "Tarco Guaman su padre", quien a su vez las había heredado de "Mayta Cápac su agüelo padre del dicho Tarco Guaman" (en Rowe ibid.: 104). Como estos datos genealógicos corroboran -en vez de contradecir- lo declarado por Acosta, y más aún por Polo, sobre la sucesión de los Incas burin, Rowe se apresuró a advertir al lector de que los términos de parentesco para "padre" y "abuelo"... "aparecen con alguna frecuencia en genealogías incas del siglo XVI con el significado de 'antepasado' en general" (Rowe, ibid.).

Pero es éste un argumento que puede considerarse ad boc, ante una evidencia nueva que contradice claramente el planteamiento crítico de origen. Rowe no facilitó ningún dato que avalara un significado de "antepasado" para los términos de "padre" y "abuelo". Por el contrario, según los dic- 
cionarios de quechua-castellano del siglo XVI (Santo Tomás 1560; Lexicógrafo anónimo 1614 [1586]) y la disertación sobre los términos quechuas de parentesco por Diego González Holguín en su Gramática (1607: 96r-99r), aunque el término machu podía significar tanto "abuelo" como "bisabuelo" y, además, "antiguo en edad" y "antepasado" o "antecesor", el término yaya ("padre") sólo significaba complementariamente "padrastro", "hermano del padre" y "señor" o "amo" (Santo Tomás 1560: 2v, 12r, 80v, 140v, 148r; Lexicógrafo anónimo 1614: L2r-L3v; González Holguín 1607: 96v). Sería raro por eso que el texto citado por Rowe pudiera entenderse como que Tarco Huaman había sido el "amo" o "señor" de Juan Tampu Usca Mayta y que el Inca Mayta Cápac fuera "antepasado" de éste pero "amo" o "señor" de Tarco Huaman, por señalar la traducción más próxima a la interpretación de Rowe; la cual deja todavía a Tarco Huaman a tan sólo una generación de distancia, o bien de Juan Tampu o bien de Mayta Cápac, si no de uno y de otro a la vez. Cabe por ello pensar que la traducción que aparece en los autos del litigio estudiado por Rowe estuvo acertada y que, en consecuencia, si Tarco Huaman fue realmente el "padre" de Juan Tampu (y no el "abuelo", como escribió Acosta) y el Inca burin Mayta Cápac fue el "abuelo" (o tal vez "bisabuelo") de éste, la dinastía burin no pudo haber reinado antes que la hanan, tal como sugieren el resumen del tratado de Polo y el texto de Acosta.

Los demás razonamientos de Rowe y de Julien contra la existencia de una diarquía entre los incas no son tampoco persuasivos. Acosta no pudo haber bebido sólo en el tratado de Polo de 1560 y en los autos del litigio oído por éste como corregidor en Cusco. En su texto se encuentra información adicional -verídica o no-, que ya he señalado: como la mención a un segundo "Topa Inga Yupangui" (del que Acosta dice claramente que fue hermano y no hijo del emperador del mismo nombre ${ }^{15}$ ) y la referencia a un hijo de "Tarco Huaman" como Inca número seis de la parcialidad burin.

Además, Acosta no pudo haber leído mal el texto de Polo, ya que el también jesuita Bernabé Cobo, quien asimismo utilizaría ese tratado para su Historia del Nuevo Mundo en el siglo XVII, tomó el texto como lo había hecho Acosta. Basándose en él, Cobo escribió que "sacando a Manco-Cápac, que como cabeza y tronco de ambas parcialidades de Hanan-Cuzco y HurinCuzco, no entraba en la división dellas, los demás reyes unos fueron de la de Hanan-Cuzco y otros de la de Hurin-Cuzco" (Cobo 1956: II, 72). Nótese el orden de las parcialidades. Cobo también escribió —en lo que es pro-

${ }^{15} \mathrm{Si}$ este personaje no es producto de una disociación con un Inca anterior, como he apuntado antes, puede tratarse del que en otras fuentes, incluido Sarmiento, es llamado "Amaru Túpac Inca" (Serpiente Topa Inga"), del que se dice que su padre llegó a designar sucesor al trono antes que a su otro hijo llamado Topa Inga (Sarmiento 1988: 115). 
bablemente otro eco de la obra original de Polo- que "Tarco Huaman" estuvo a punto de ser Inca, si es que no llegó a serlo brevemente, al ser el preferido de una facción de la elite imperial frente a su hermano "Cápac Yupanqui" (ibid.: 71). La diferencia con el texto de Acosta radica en que, a pesar de lo escrito, Cobo - como Sarmiento, Cieza de León y Betanzosinterpretó que los reyes burin habrían precedido a los hanan. La idea de una diarquía no le podía caber tampoco a él en la cabeza (Cobo, ibid:: 72).

Las otras obras de Polo aducidas por Rowe no quitan valor a lo afirmado en ese tratado de 1560 y leído por Acosta y por Cobo. Su informe de 1561 sobre la perpetuidad de las encomiendas en el Perú no dice nada realmente que lo contradiga. Frases como "cuando hazían inga que era su Rey" o "los tributos que éstos daban al señor soberano, que era el inga" pueden hacer referencia al Inca de la parcialidad hanan, que era el Inca visible, el que representaba a la totalidad política de Cusco y el Tawantinsuyu. En cuanto a la declaración de 1572, a propósito de la investigación ordenada por el virrey Toledo, no puede tener más valor que lo afirmado por Polo en 1560 y lo escrito por Acosta después. Como es sabido (Wedin 1966: 81-82; Hemming 1970: 411-416), con esa investigación Toledo se proponía nada menos que deslegitimar el derecho de los Incas al gobierno del Perú, con el fin de afianzar la autoridad del régimen colonial. El asunto era políticamente delicado y, como los demás testigos llamados a declarar -incluidos los indígenas-, Polo no podía contradecir sin riesgos lo concluido en la investigación. Aun así, para mayor seguridad, Toledo se sirvió de un intérprete para los indígenas, Gonzalo Gómez Jiménez, que después se revelaría como un falsario (Murra 1993: 30-32). Polo se limitó a asentir a lo que le preguntaron, sin añadir nada de su parte excepto sobre los cuerpos embalsamados de Incas y sus reinas que, siendo corregidor, había descubierto unos años antes en Cusco. En este contexto marginal a la investigación, sus palabras fueron coherentes con lo afirmado en 1560: dijo que unos cuerpos eran de "Hanan Cuzco" y otros, de "Urin Cuzco", en este orden, que es el mismo que el de los reyes nombrados en el tratado resumido de 1560 , esto es, el orden jerárquico de las dos parcialidades en la estructura social y política de la capital de los incas (Polo de Ondegardo en Toledo 1882: 255-257).

\section{Estructura e historia en el Perú Prehispánico}

Aunque rechazando la existencia de una diarquía, Rowe y Julien -como también Rostworowski, Pärssinen y Hiltunen- han aceptado del planteamiento de Zuidema que los linajes reales no pudieron haber surgido todos en sucesión ordenada, a medida que moría cada uno de sus progenitores. También han aceptado que parte del discurso narrativo en las historias recogidas por 
los españoles - la relativa a los tiempos más remotos- no puede tomarse literalmente, sino como una elaboración después de los hechos a fin de satisfacer los intereses políticos de una facción de los incas. Unos cien años antes de la invasión española, la llegada al poder de esta facción habría causado no sólo esa relectura del pasado sino también grandes transformaciones en Cusco y en el entonces naciente imperio, así como la constitución de la mayoría de los linajes reales (Rowe 1967, 1985a; Julien 2000: 7-10, 254-268; Rostworowski 1983: 130-131, 138-145; 1988: 50-59; Pärssinen 1992: 71-140; Hiltunen 1999: 25-30, 212-218).

Después de ese gran cambio, sin embargo, la forma de gobierno habría continuado siendo fundamentalmente la monarquía; los cinco o seis últimos soberanos nombrados en las distintas listas habrían sido históricos en nuestro sentido de la expresión; y los linajes reales habrían surgido secuencialmente a la muerte de cada uno de esos monarcas, sumando en total hasta once, doce o más linajes cuando se produjo la llegada de los españoles. Así, aunque algo distanciados del historicismo anterior a los años sesenta, estos investigadores siguen sin dar la debida importancia a la cosmología inca, como tampoco al hecho de que en Cusco, en 1532, había constituidos, como corporaciones, sólo diez linajes reales y ninguno más, y éstos estaban divididos en las dos mitades ya conocidas. Tampoco contemplan la posibilidad - salvo por Rostworowski (1983: 139, 155-157)— de que la pertenencia a esos linajes fuera matrilineal y no (o no sólo) patrilineal, como sugiere el testimonio de Las Casas y la genealogía de algunos de los Incas míticos, como YáhuarHuacca.

La base de este posicionamiento es que estos investigadores - al igual que los anti-estructuralistas Schaedel, Conrad y Demarest, y Patterson- continúan aceptando como fuentes históricas las narraciones españolas, al menos para esos cien últimos años de tiempo prehispánico. A ello les animan tal vez las circunstancias metodológicas que apunté al principio, especialmente la actitud ahistórica de Zuidema y lo abstruso y a veces poco riguroso y cambiante de sus argumentaciones. Asumen que los españoles que escribieron sobre la historia de los incas en las primeras décadas de régimen colonial entendieron o transcribieron bastante fielmente la tradición indígena de esa historia, como la registrada en lo que Cieza llamó "quipos y romances"; otra cosa es que esa tradición pudo haber tenido diversas versiones, lo que explicaría las divergencias entre los textos españoles más fiables.

Pärssinen, en la estela de John Murra (1975), ha creído superar este paradigma epistemológico recurriendo a fuentes sobre las provincias del Imperio como medio de verificar o suplantar las relativas a su centro neurálgico (Pärssinen 1992: 12-15, 21-24). Sin embargo, su actitud hacia ellas no ha sido muy diferente de la de los demás investigadores hacia los textos de 
los que él desconfía o que ha evitado. El problema es más profundo que el de una elección adecuada de fuentes, con ser éste importante. Julien, con el precedente de Rowe (1985b), ha realizado un meritorio trabajo de búsqueda de la conexión entre las dos "historiografías", la indígena y la española, en su caso creyendo encontrar lo fundamental de la primera en lo más frecuente que se lee en la segunda (Julien 2000: 49-232). Muchas de sus conclusiones son valiosas, especialmente para el pasado incaico inmediatamente anterior a la llegada de Pizarro y sus hombres, que los estructuralistas han desdeñado. Pero ya hemos visto cómo Cieza, uno de los autores españoles más respetables, no se limitó a poner en castellano lo que le decían sus fuentes: pues también reflexionó sobre ello, tomó decisiones y compuso. Recuérdese asimismo el interés de Betanzos por realzar el status de su esposa, un prejuicio sobre el que ha advertido la propia Julien. En cuanto a Sarmiento —otro autor muy citado, base de lo que Rowe llamó en 1945 la "standard version" de la historia de los incas-, vino a confesar, aunque oblicuamente, haber hecho lo mismo que Cieza:

Y así examinando de toda condición de estados de los más prudentes y ancianos, de quien se tiene más crédito, saqué y recopilé la presente historia, refiriendo las declaraciones y dichos de unos a sus enemigos, digo del bando contrario, porque se acaudillan por bandos, y pidiendo a cada uno memorial por sí de su linaje y del de su contrario. Y estos memoriales, que todos están en mi poder, refiriéndolos y corrigiéndolos con sus contrarios y últimamente ratificándolos en presencia de todos los bandos en público, con juramento por autoridad de juez, y con lenguas expertas generales, y muy curiosos y fieles intérpretes, también juramentados, se ha afinado lo que aquí va escrito (Sarmiento 1988: 49-50).

Sarmiento, como tampoco Betanzos ni Cieza, no entendió el concepto inca de tiempo y de historia; ninguno de los tres llegó a comprender siquiera la organización social y política que era su fundamento: por ejemplo, esos mismos "bandos" o "linajes" ante los cuales dice el primero que quedó ratificada su Historia "en público", "con juramento por autoridad de juez". Afortunadamente, ellos mismos y otros autores ofrecen datos con que intentar encontrar lo que la mayoría apenas tuvo interés en buscar. Y entre ellos están precisamente los de Polo de Ondegardo y Acosta, que no por singulares deben ser considerados poco fiables. Los dos recogieron la tradición "histórica" indígena que atribuía las dos parcialidades y la diarquía a un personaje llamado Manco Cápac, el presunto fundador de Cusco: una información que concuerda con la versión de Martín de Murúa sobre la constitución de los linajes. Habría sido entonces el Inca fundador, y no el Inca número nueve (a decir de Las Casas) o el número diez (a decir de Gutiérrez de Santa Clara), el supuesto creador de tal estructura de diez corporaciones de la elite imperial en la capital. 
Esta concordancia entre Polo, Acosta y Murúa —que ni Zuidema ni Duviols han tenido suficientemente en cuenta- permite a su vez aclarar la ubicación de los Incas en los cómputos sobre la historia del Perú prehispánico transmitidos por Montesinos, Valera, Sarmiento y Guaman Poma. Si Manco Cápac hubiera sido, en efecto, no sólo el gran legislador sobre los linajes sino también, lógicamente, el creador de su marco institucional (el orden social y político esbozado por Polo y Acosta), sería entonces él quien personificara, mejor que ningún otro Inca, al noveno pachakuti en la cuenta milenaria de Montesinos y en la de Valera, marcando un cambio de época a los 4.500 años desde el Diluvio Universal. Puede entonces superarse sin dificultad la aparente contradicción entre esta cuenta y la de Sarmiento y Guaman Poma.

Montesinos, como Polo y Vázquez de Espinosa, habría estado en lo cierto al interpretar que los Incás, según la tradición nativa (esto es, los diez de la estructura más un "rey Pachacuti"), se habían sucedido a lo largo de quinientos años hasta la llegada de los españoles. Sin embargo, habría errado al situar el comienzo de esa sucesión en el año 4.000 del Diluvio y no en el 4.500. Un indicio significativo de este error, y de cuál pudo haber sido la cronología original, es que Montesinos incluyó también en su texto el tema del gran Inca conquistador y legislador (el tema del noveno "rey Pachacuti", en la versión de Valera), pero ubicándolo entre ese año 4.000 y la invasión española: un plazo de tiempo demasiado breve según el mismo autor - de sólo quinientos años-, que no puede dejar sitio para un rey Pachacuti adicional a los ocho ya enumerados por él antes de ese acontecimiento. A menos, claro está, que la cronología original, tal como llegó a sus manos, abarcara hasta los 5.000 años y que en ella el noveno pachakuti sirviera para señalar el comienzo revolucionario de la época de los Incas en el año 4.500 .

El error de Sarmiento y de Guaman Poma habría sido otro: el de desdoblar en una serie de diez Incas (en dos dinastías sucesivas), a lo largo de un periodo de mil años, lo que originalmente habría sido una estructura de cinco diarquías (o dos dinastías paralelas de cinco soberanos cada una) en un periodo de quinientos años, a razón de cien años por diarquía. Esos quinientos años corresponderían a los transcurridos entre el 4.500 y el 5.000 en la cronología milenaria subyacente al texto de Montesinos; es decir, corresponderían a la época entre el Pachacuti noveno (el Inca conquistador y legislador, Manco Cápac) y el décimo (la crisis sucesoria del Imperio y la invasión española). Aunque Montesinos no llegó a desdoblar la duración de esta época, como habían hecho Sarmiento y Guaman Poma, sin embargo ignoraba (o no tuvo en cuenta) el sentido que tenía el principio dual banan/burin en la cultura indígena y su impacto en esa cronología. El resultado de esta deficiencia fue doble: por un lado, Montesinos concedió a los once Incas de la 
estructura los quinientos años que les correspondían, pero los alineó a uno detrás de otro; por otro lado, para el pasado preincaico, desdobló en secuencias de al menos veinte reyes sucesivos por cada "sol" o edad lo que eran originalmente secuencias de diez diarquías por cada "sol", o cinco diarquías entre un pachakuti y el siguiente. Cada pachakuti marcaba una alteración de $180^{\circ}$ en el contenido de las posiciones banan y burin: quienes habían estado "arriba" en la época anterior pasaban a estar "debajo" en la nueva, y quienes habían estado "debajo" pasaban a estar "arriba".

Este esquema cíclico original (quinquepartito y, por efecto del dualismo banan/burin, decimal a la vez) sería parte de una estructura aún más incluyente, asimismo quinquepartita y decimal, que abarcara al presente del virreinato y al futuro, como revela el análisis de Ossio, Wachtel y Szemińsky de la obra de Guaman Poma. A las cinco edades o "soles" (o diez épocas, jalonadas por otros tantos pachakutis), transcurridos hasta la crisis del imperio inca, les sucederían otros cinco periodos hasta el futuro soñado por el autor, el de una cristiandad universal presidida por el rey de España. No obstante, en coherencia con el concepto de alternancia anterior, puede pensarse que estos cinco nuevos periodos, más que otra edad o "sol" (el sexto), constituirían sólo la mitad del mismo: una época ("quinientos años") hasta un nuevo pachakuti, el undécimo. Si la caída del imperio inca y la conquista española habían supuesto un vuelco copernicano en el orden social y político andino -generando un "mundo al revés", en palabras de Guaman Poma: el paso a la posición banan de gentes extrañas e innobles-, el futuro subsiguiente depararía otro vuelco, revirtiendo el anterior y devolviendo a la posición banan a los nobles y autóctonos del Tawantinsuyu. Encontramos así, a este nivel más general (o más profundo, según se mire), el simple concepto de sólo dos tiempos y dos mundos alternando entre sí —en un movimiento pendular, como habría dicho Leach (1997: 127)—, de nuevo por efecto del dualismo hanan/hurin, un dualismo cosmológico sobre el presente.

En un registro distinto, fuera de esta compleja estructura conceptual acerca del tiempo y de la historia, de varios niveles, estarían los Incas históricos bajo nuestro punto de vista, a quienes conocieron los primeros españoles o los informantes de éstos. Para la época prehispánica, la historicidad sería mayor cuanto más se acercara la vida o la memoria de estos personajes a la llegada de los españoles. Los más seguros son, por eso, Atahuallpa y Huáscar y, tras ellos, el padre de ambos, Huayna Cápac. Es para este último periodo de la historia de los incas para el que el método de Rowe y de Julien tiene valor. Pero sería una historicidad que habría que entender en conexión con la estructura mencionada; o por decirlo con las expresivas palabras de Karl Marx en su famoso estudio del Dieciocho de Brumario de Luis Bonaparte: 
Los hombres hacen su propia historia, pero no la hacen arbitrariamente, bajo circunstancias elegidas por ellos mismos, sino bajo circunstancias directamente dadas y heredadas del pasado. La tradición de todas las generaciones muertas oprime como una pesadilla el cerebro de los vivos (Marx 1971: 11).

O en palabras de Marshall Sahlins: "la acción empieza y termina en estructura [...]. El proceso histórico se desenvuelve como un proceso continuo y recíproco entre la práctica de la estructura y la estructura de la práctica" (Sahlins 1981: 72) ${ }^{16}$. Más allá de Huayna Cápac, empezamos a encontrarnos con otra cosa, especialmente a medida que se avanza en la conquista española y el registro de la historia indígena, fuera oral o mediante khipus, empieza a hacerse cada vez más equívoco o impreciso, al menos para las sucesiones dinásticas (¿fueron "Inca Yupanqui” y "Túpac Inca”, en la obra de Cieza, el mismo personaje o dos Incas distintos?); en su lugar, la estructura mítica, más fácil de difundir, comienza a poner su propio orden y significado sobre lo acontecido.

\section{BIBLIOGRAFÍA CITADA}

ACOSTA, JOSÉ DE. 1987. Historia natural y moral de las Indias [1590]. Edición de José Alcina Franch. Madrid: Historia 16.

ANÓNIMO. 1992. Relación de las costumbres antiguas de los naturales del Perú [ca. 1589], atribuida a Blas Valera, en Henrique Urbano y Ana Sánchez (eds.), Antigüedades del Perú: 43-122. Madrid: Historia 16.

ARNOLDSSON, SVERKER. 1965. Los momentos bistóricos de América según la bistoriografía bispano-americana del periodo colonial [1956]. Segunda edición. Madrid: Ínsula.

BAUDin, Louis. 1928. L'Empire socialiste des Inka. París: Institut d'Ethnologie.

BAUER, BRIAN. 1992. The Development of the Inca State. Austin: The University of Texas Press.

Betanzos, JuAn Díez DE. 1987. Suma y narración de los incas [1557]. Edición de María del Carmen Martín Rubio. Madrid: Atlas.

BRUNDAGE, BURR C. 1963. Empire of the Inca. Norman, Oklahoma: University of Oklahoma Press.

-. 1966. "Response to Zuidema's Review of Empire of the Inca". American Anthropologist 68 (1): 229-231.

Cabello Balboa, Miguel. 1920. Historia del Perú bajo la dominación de los Incas [1586]. Edición de Horacio H. Urteaga. Lima: Sanmartí y Cía.

CIEZA DE LEÓN, PEDRo DE. 1985. El señorío de los incas [1550]. Edición de Manuel Ballesteros Gaibrois. Madrid: Historia 16.

CoBo, Bernabé. 1956. Historia del Nuevo Mundo [1653]. Edición de Francisco Mateos. Madrid: Atlas.

16 Traducción propia de: "Action begins and ends in structure [...]. The historical process unfolds as a continuous and reciprocal movement between the practice of the structure and the structure of the practice". 
CONRAD, GeOfFrey W., y ARTHUR A. Demarest. 1984. Religion and Empire: The Dynamics of Aztec and Inca Expansionism. Cambridge: Cambridge University Press.

CORREAS, GONZALO. 1924. Vocabulario de refranes y frases proverbiales $y$ otras fórmulas comunes de la lengua castellana [ca. 1637]. Madrid: Tipografía de la Revista de Archivos, Bibliotecas y Museos.

D'Altroy, Terence N. 2002. The Incas. Malden, Massachusetts: Blackwell.

D'Altroy, Terence N., y Christine A. Hastorf. 1984. "The Distribution and Contents of Inca State Storehouses in the Xauxa Region of Peru". American Antiquity 49 (2): 334-349.

D'Altroy, Terence N., y Timothy EARle. 1985. "Staple Finance, Wealth Finance, and Storage in the Inka Political Economy". Current Antrbropology 26 (2): 187-206.

DíEz DE SAN MIGUEL, GARCI. 1964. Visita becha a la provincia de Chucuito [...] en el año 1567. Edición de Waldemar Espinoza Soriano. Lima: Casa de la Cultura del Perú.

Duviols, PIERRE. 1980a. "Algunas reflexiones acerca de la tesis de la estructura dual del poder incaico". Historica 4 (2): 183-196.

-. 1980b. "Periodización y política: la historia según Guaman Poma de Ayala". Bulletin de l'Institut Français d'Études Andines IX (3-4): 1-18.

-. 1980-81. "Religions et sociétés de l'Amérique du Sud (région andine)". Annuaire de l'École Pratique des Hautes Études, Ve section (section religieuse) LXXXIX: 109-115.

EliAde, MiRCEA. 1999. El mito del eterno retorno [1951]. Madrid: Alianza; Buenos Aires: Emecé.

ESPINOZA SORIANO, WALDEMAR. 1969. "El reyno aymara de Quillaca-Asanaque, siglos XV y XVI". Revista del Museo Nacional 45: 175-274.

-. 1981. "El memorial de Charcas. 'Crónica' inédita de 1582". Cantuta 4: 117-152.

GARCILASO DE LA VEGA, INCA. 1991. Comentarios reales de los Incas [1609]. Edición de Carlos Araníbar. Lima: Fondo de Cultura Económica.

González Holguín, Diego. 1607. Gramática y Arte nueva de la lengua general de todo el Perú, llamada lengua Qquichua, o lengua del Inca. Lima: Francisco del Canto.

GuAMAN POMA DE AYALA, FELIPE. 1980. El primer nueva corónica y buen gobierno [1615]. Edición de J. V. Murra, R. Adorno y J. L. Urioste. México, D. F.: Siglo XXI.

GutiÉRREZ DE SANTA ClARA, PEDRO. 1963-1964. Quinquenarios o bistoria de las guerras civiles del Perú (1544-1548) y de otros sucesos de las Indias [ca. 1603]. Edición de Juan Pérez de Tudela Bueso en Biblioteca de Autores Españoles (Continuación), tomos CLXV (pp. 131-388), CLXVI y CLXVII (pp. 1-225). Madrid: Atlas.

Hemming, John. 1970. The Conquest of the Incas. San Diego: Harvest/Harcourt Brace Jovanovich.

Hiltunen, Juha J. 1999. Ancient Kings of Peru: The Reliability of the Chronicle of Fernando de Montesinos. Helsinki: Suomen Historiallinen Seura.

ImBELloni, José. 1941. "La capaccuna de Montesinos, después de cien años de discusiones e hipótesis (1840-1940)". Anales del Instituto de Etnografia Americana II: 259-354.

- 1944. "La tradición peruana de las Cuatro Edades del Mundo en una obra rarísima impresa en Lima en el año 1630". Anales del Instituto de Etnografía Americana V: 55-94.

- 1946. Pachacuti IX (El Inkario crítico). Buenos Aires: Humanior.

JIMÉNEZ DE LA ESPADA, MARCOS. 1882. "Dedicatoria al Ilmo. Sr. D. Cesáreo Fernández Duro", en Memorias antiguas bistoriales y politicas del Perú, de Fernando Montesinos [...], Colección de Libros Españoles Raros o Curiosos 16: vii-xxxii. Madrid: Imprenta de Miguel Ginesta. 
JULIEN, CATHERINE. 2000. Reading Inca History. Iowa City: University of Iowa Press.

Kolata, Alan L. 1993. The Tiwanaku: Portrait of an Andean Civilization. Cambridge, EE.UU., y Oxford, Reino Unido: Blackwell.

LARA, JESÚs. 1997. Diccionario qheshwa-castellano, castellano-qheshwa. Cuarta edición. La Paz y Cochabamba: Los Amigos del Libro.

Las CASAS, BARTOlOmÉ DE. 1892. De las antiguas gentes del Perú [ca. 1561]. Edición de Marcos Jiménez de la Espada en Colección de Libros Españoles Raros o Curiosos 21. Madrid: Tipografía de Manuel G. Hernández.

LEACH, Edmund. 1997. "Two Essays Concerning the Symbolic Representation of Time" [1953], en Rethinking Anthropology, del mismo autor: 124-136. Londres: The Athlone Press.

LeXICÓGRAFo ANÓNImo. 1614. Arte, y vocabulario en la lengua general del Perú llamada Quichua, y en la lengua española [1586]. Lima: Francisco del Canto.

MARKAM, SIR ClEmENTS R. 1910. The Incas of Peru. Londres: Smith, Elder \& Co.

-. 1920. "Introduction", en Memorias antiguas historiales del Perú by Fernando Montesinos: 3-15. Londres: Hakluyt Society.

MARTín RUBIO, MARÍA DEL CARMEN. 1987. "Prólogo" a Suma y narración de los incas, de Juan Díez de Betanzos: IX-XXX. Madrid: Atlas.

MARX, KARL. 1971. El dieciocho brumario de Luis Bonaparte [1852]. Traducción de O. P. Safont. Barcelona: Ariel.

Matienzo, JuAn DE. 1967. Gobierno del Perú con todas las cosas pertenecientes a él y a su bistoria [1567]. Edición de Guillermo Lohmann-Villena. París y Lima: Institut Français d'Études Andines.

MEANS, Philip A. 1920. "Introduction", en Memorias antiguas historiales del Perú by Fernando Montesinos: xi-lii. Londres: Hakluyt Society.

-. 1931. Ancient Civilizations of Peru. Nueva York: Gordian Press.

Molina DE CusCo, CRISTÓBAl DE. 1989. "Relación de las fábulas i ritos de los ingas" [ca. 1575], en H. Urbano y P. Duviols (eds.), Fábulas y mitos de los incas: 47-134. Madrid: Historia 16.

MONTESINOS, FERnANDO. 1882. "Memorias antiguas historiales y políticas del Perú" [1644]. Edición de Marcos Jiménez de la Espada en Colección de Libros Españoles Raros o Curiosos 16: 1-176. Madrid: Imprenta de Miguel Ginesta.

MURRA, JOHN V. 1975a Formaciones económicas y políticas del mundo andino. Lima: Instituto de Estudios Peruanos.

—. 1975b. "Las autoridades étnicas tradicionales en el alto Huallaga [1967], en Formaciones económicas y políticas del mundo andino: 171-192. Lima: Instituto de Estudios Peruanos

-. 1975c. "Un reino aymara en 1567" [1968, 1970], en Formaciones económicas y políticas del mundo andino: 193-223. Lima: Instituto de Estudios Peruanos.

- 1978. La organización económica del Estado inca [1955]. Traducción de Daniel R. Wagner. México, D. F.: Siglo XXI.

—. 1993. "El doctor Barros de San Millán: Defensa de los 'señores naturales' en los Andes", en Solemne Investidura de Doctor Honoris Causa al Professor John V. Murra: 21-39. Barcelona: Universitat de Barcelona.

MuRÚA, MARTín DE. 1987. Historia general del Perú [1613]. Edición de Manuel Ballesteros Gaibrois. Madrid: Historia 16.

Netherly, Patricia. 1984. "The Management of Late Andean Irrigation Systems on the North Coast of Peru". American Antiquity 49 (2): 227-254. 
Ossio, Juan M. 1973. "Guamán Poma: Nueva Corónica o Carta al Rey. Un intento de aproximación a las categorías del pensamiento del mundo andino", en J. M. Ossio (ed.), Ideología mediánica del mundo andino: 153-213. Lima: Ignacio Prado Pastor.

- 1977. "Las cinco edades del mundo según Felipe Guamán Poma de Ayala". Revista de la Universidad Católica del Perú 2: 43-58.

PÄrSSINEN, MARTTI. 1992. Tawantinsuyu: The Inca State and Its Political Organization. Helsinki: Societas Historica Finlandiae.

PATTERSON, THOMAS C. 1991. The Inca Empire: The Formation and Disintegration of a Pre-Capitalist State. Oxford y Nueva York: Berg.

PÉREZ BOCANEGRA, JUAN. 1631. Ritual formulario e institución de curas para administrar a los naturales de este reyno los santos sacramentos del baptismo, confirmación, eucaristía y viático, penitencia, extremaunción y matrimonio, con advertencias muy necesarias. Lima: Gerónymo de Contreras.

POLO DE ONDEGARDO. 1982. "Los errores y supersticiones de los indios" [ca. 1560], en Juan Guillermo Durán (ed.), El catecismo del III Concilio Provincial de Lima y sus complementos pastorales (1584-1585), Estudio Preliminar, Textos, Notas: 459-478. Buenos Aires: Editorial "El Derecho".

POPPER, KARL R. 1991. The Poverty of Historicism [1944-1945]. Londres y Nueva York: Routledge.

PORRAS BARRENECHEA, RAúl. 1948. El cronista indio Felipe Huaman Poma de Ayala. Lima: Lumen.

- 1986. Los cronistas del Perú (1528-1650) y otros ensayos [1962]. Lima: Banco de Crédito del Perú.

Riva-AgüERO, JosÉ DE LA. 1965. La Historia en el Perú [1910]. Tercera edición, revisada y corregida en Obras Completas IV. Lima: Pontificia Universidad Católica del Perú.

ROSTWOROWSKI DE DíEZ CANSECO, MARÍA. 1983. Estructuras andinas del poder: Ideología religiosa y política. Lima: Instituto de Estudios Peruanos.

-. 1988. Historia del Tawantinsuyu. Lima: Instituto de Estudios Peruanos.

Rowe, JoHN H. 1945. "Absolute Chronology in the Andean Area". American Antiquity 10 (3): $265-284$.

-. 1946. "Inca Culture at the Time of the Spanish Conquest", en Julian Steward (ed.), Handbook of South American Indians 2, The Andean Civilizations: 183-330. Washington: Smithsonian Institution, Bureau of American Ethnology.

- 1958. "The Age Grades of the Inca Census", en Actas del XXXI Congreso Internacional de Americanistas, Miscellanea Paul Rivet Octogenaria Dicata II: 499-522. México: Universidad Nacional Autónoma de México.

- 1967. "What Kind of a Settlement was Inca Cuzco?". Ñawpa Pacha 5: 59-76.

-. 1985a. "La constitución inca del Cuzco". Historica 9 (1): 35-73.

-. 1985b. "Probanza de los incas nietos de los conquistadores". Historica 9 (2): 193-245.

-. 1993-94. "La supuesta 'diarquía' de los incas". Revista del Instituto Americano de Arte 14: 99-107.

SAHLINS, MARSHALl. 1981. Historical Metaphors and Mytbical Realities: Structure in the Early History of the Sandwich Islands Kingdom. Ann Arbor, Michigan: The University of Michigan Press.

SALOMON, FRANK. 1986. Native Lords of Quito in the Age of the Incas: The Political Economy of North Andean Chiefdoms. Cambridge: Cambridge University Press.

SANTO TOMÁs, Domingo DE. 1560. Lexicon, o vocabulario de la lengua general del Perú. Valladolid: Francisco Fernández de Córdova. 
Sarmiento De Gamboa, Pedro. 1988. Historia de los incas [1572]. Madrid: MiraguanoPolifemo.

SCHAEDEL, RichaRd P. 1978. "Early State of the Incas", en J. M. Claessen y P. Skalník (eds.), The Early State: 289-320. La Haya, París y Nueva York: Mouton.

SZEMIŃSKI, JAN. 1982-1984. "Las generaciones del mundo según don Felipe Guaman Poma de Ayala". Estudios Latinoamericanos 9: 89-123.

TOLEDO, VIRREY FRANCISCO DE. 1882. Informaciones acerca del señorí y gobierno de los ingas [1570-1572]. Edición de Marcos Jiménez de la Espada en Colección de Libros Españoles Raros o Curiosos 16: 177-259. Madrid: Imprenta de Miguel Ginesta.

Uhle, MAX. 1912. "Los orígenes de los incas", en Actas del XVII ${ }^{\circ}$ Congreso Internacional de Americanistas (1910), Vol. I: 302-353. Buenos Aires: Imprenta de Corci Hermanos.

VÁZQueZ DE ESPINOSA, ANTONIO. 1969. Compendio y descripción de las Indias Occidentales [1629]. Edición de B. Velasco Bayón en Biblioteca de Autores Españoles (Continuación), Vol. 231. Madrid: Atlas.

VILlARÍAS ROBLES, JUAN J. R. 1998. El sistema económico del imperio inca: Historia crítica de una controversia. Madrid: CSIC, Colección Tierra Nueva e Cielo Nuevo.

WACHTEL, NATHAN. 1966. "Structuralisme et histoire à propos de l'organisation sociale de Cuzco". Annales, E.S.C. 21 (1): 71-94.

- 1971a. "Pensée sauvage et acculturation: l'espace et le temps chez Felipe Guaman Poma de Ayala et l'Inca Garcilaso de la Vega". Annales, E.S.C. 26 (3-4): 793-840.

- 1971b. La vision des vaincus: Les indiens du Pérou devant la conquête espagnole. París: Gallimard.

WEDIN, ÅKE. 1963. La cronología de la bistoria incaica: estudio crítico. Madrid: Ínsula.

- 1965. El sistema decimal en el imperio incaico. Madrid: Ínsula.

- 1966. El concepto de lo incaico y las fuentes. Upsala: Studia Historica Gothoburgensia.

Zuidema, REINER TOM. 1964. The Ceque System of Cuzco: The Social Organization of the Capital of the Inca. Traducción al inglés de Eva M. Hooykas. Leiden: E. J. Brill, Supplement to Vol. 50 of International Archives of Ethnography.

- 1973. Una interpretación alterna de la historia incaica [1964], en Juan M. Ossio (ed.), Ideología mesiánica del mundo andino: 2-33. Lima: Ignacio Prado Pastor.

- 1977. "Mito e historia en el antiguo Perú". Allpanchis Phuturinqa 10: 15-52.

-. 1989a. "El origen del imperio inca" [1967], en Manuel Burga (ed.), Reyes y guerreros: Ensayos de cultura andina: 193-218. Lima: Fomciencias.

- 1989b. "Parentesco y culto a los antepasados en tres comunidades peruanas [1973]. Una relación de Hernández Príncipe de 1622", en Manuel Burga (ed.), Reyes y guerreros: Ensayos de cultura andina: 117-143. Lima: Fomciencias.

—. 1989c. "El parentesco inca: una nueva visión téorica" [1977], en Manuel Burga (ed.), Reyes y guerreros: Ensayos de cultura andina: 54-116. Lima: Fomciencias.

-. 1990. Inca Civilization in Cuzco [1986]. Traducción al inglés de Jean-Jacques Decoster. Austin: University of Texas Press. 